NBER WORKING PAPER SERIES

\title{
CREATING A BIGGER PIE? THE EFFECTS OF EMPLOYEE OWNERSHIP, PROFIT SHARING, AND STOCK OPTIONS ON WORKPLACE PERFORMANCE
}

\author{
Joseph R. Blasi \\ Richard B. Freeman \\ Chris Mackin \\ Douglas L. Kruse \\ Working Paper 14230 \\ http://www.nber.org/papers/w14230 \\ NATIONAL BUREAU OF ECONOMIC RESEARCH \\ 1050 Massachusetts Avenue \\ Cambridge, MA 02138 \\ August 2008
}

This paper was presented at the Russell Sage/NBER conference in New York City, October 2006, and benefited from comments by Casey Ichniowski and other participants. An earlier version was presented at the Labor and Employment Relations conference, Boston, Massachusetts, January 5-8, 2006. This research is supported by a grant from the Russell Sage Foundation and the Rockefeller Foundation. The National Opinion Research Center at the University of Chicago provided valuable assistance with the U. S. General Social Survey segment that forms the basis for some of the analysis. Refen Koh, Rhokeun Park, Michelle Pinheiro, and Patricia Berhau provided excellent assistance in survey scanning, entry, and verification. The views expressed herein are those of the author(s) and do not necessarily reflect the views of the National Bureau of Economic Research.

NBER working papers are circulated for discussion and comment purposes. They have not been peerreviewed or been subject to the review by the NBER Board of Directors that accompanies official NBER publications.

(C) 2008 by Joseph R. Blasi, Richard B. Freeman, Chris Mackin, and Douglas L. Kruse. All rights reserved. Short sections of text, not to exceed two paragraphs, may be quoted without explicit permission provided that full credit, including $(\mathcal{O}$ notice, is given to the source. 
Creating a Bigger Pie? The Effects of Employee Ownership, Profit Sharing, and Stock Options on Workplace Performance

Joseph R. Blasi, Richard B. Freeman, Chris Mackin, and Douglas L. Kruse

NBER Working Paper No. 14230

August 2008

JEL No. J33,J54,L23,L25

\section{ABSTRACT}

This paper uses data from NBER surveys of over 40,000 employees in hundreds of facilities in 14 firms and from employees on the 2002 and 2006 General Social Surveys to explore how shared compensation affects turnover, absenteeism, loyalty, worker effort, and other outcomes affecting workplace performance.

The empirical analysis shows that shared capitalism has beneficial effects on all outcomes save for absenteeism and that it has its strongest effects on turnover, loyalty, and worker effort when it is combined with: a) high-performance work policies (employee involvement, training, and job security), b) low levels of supervision, and c) fixed wages that are at or above market level. Most workers report that cash incentives, stock options, ESOP stock, and ESPP participation motivate them to work harder. The interaction of the effects of shared capitalism with other corporate policies suggests that the various shared capitalist and other policies may operate through a latent variable, "corporate culture".

Joseph R. Blasi

Rutgers University

School of management and Labor Relations

Levin Building

New Brunswick, NJ 08544

and NBER

jrbru@hotmail.com

Richard B. Freeman

NBER

1050 Massachusetts Avenue

Cambridge, MA 02138

freeman@nber.org

\author{
Chris Mackin \\ Ownership Associates \\ cm@ownershipassociates.com \\ Douglas L. Kruse \\ School of Management and Labor Relations \\ Rutgers University \\ 94 Rockafeller Road \\ Piscataway, NJ 08854 \\ and NBER \\ dkruse@rci.rutgers.edu
}


Cooperation aims to increase the margin from which the increment of gain is to be drawn. It makes industry more productive; it gives the employer somewhat more, and to the laborer much more than they now receive...All the workmen with their employers constitute collectively an exceptionally good entrepreneur... The survival of full cooperation in the long rivalry of systems depends on its power to excel other systems ...If in the comparison with other systems, it is shown that it ought to survive, it will do so, and that regardless of initial failures -- John Bates Clark, The Philosophy of Wealth 1886

One hundred twenty years ago John Bates Clark, one of the founders of the American Economic Association, developer of marginal productivity theory, and the person for whom the prestigious Bates Clark Award is named, developed a vision of shared capitalism - the cooperative plan -- and laid out a key test for this form of capitalist enterprise, its ability to survive in competition with other forms. In his 1886 book The Philosophy of Wealth, Clark said that he wanted "to take the workman permanently out of the position in which his gain is his employer's loss” through profit sharing and stock ownership by the workers. His solution to workers’ risk aversion and lack of credit and personal funds to invest in capital was that the firm would pay profit shares to workers in the form of stock, which would make profit sharing a gradual vehicle for employee ownership. ${ }^{1}$ Clark underlined the need for skilled management and committed investors and stressed that access to new capital investment was critical to the success of such enterprises. He also noted the need for a cooperative management culture in these corporations. Clark’s views suggest that forms of shared capitalism that combine profit sharing and employee ownership without personal worker financing in a cooperative corporate setting would positively affect workplace performance and company success. Clark’s interest in shared capitalism was mirrored in

\footnotetext{
${ }^{1}$ Adam Smith (1776 ) credited the incentive of shared capitalism with improved economic performance for the French Metayers or sharecroppers where the owner of the land and the sharecropper divided the produce equally after capital investments: "Such tenants, being freemen, are capable of acquiring property, and having a certain proportion of the produce of the land, they have a plain interest that the whole produce should be as great as possible, in order that their own proportion may be so" (quoted in Laffont and Martimort 2002: 10). He stressed that sharecroppers would not risk their own capital to improve the proprietor's land without offering any resolution to this problem.
} 
the first volume of the American Economic Review, which contained extensive articles on cooperative economic relations in New England and Minneapolis in issues 4 and $5 .^{2}$

This paper analyzes the relationship of various forms of shared capitalist compensation to six workplace outcomes - turnover, absenteeism, perceived effort of co-workers, loyalty to the firm, willingness to work hard, and frequency of worker suggestions to improve productivity—from the perspective of the “John Bates Clark vision” of shared capitalism. We also examine employee responses to questions about their response to shared capitalist incentives. Our analysis uses two datasets: one from the 2002 and 2006 General Social Surveys (GSS), which cover 2430 persons in for-profit firms from a nationally representative sample; and an NBER sponsored firm based survey of 41,206 employees at 320 worksites in 14 companies for whom profit/gain sharing, a wide variety of employee ownership vehicles, and broad-based stock options are a key part of their compensation systems. We conducted the NBER survey over the 2001-2006 period, adding firms as they agreed to participate. We began our survey by selecting companies that varied in size, industry, and type of shared capitalism program, but our final sample is non-representative. Many firms refused our requests to run the survey; and we lost two large firms, which had agreed to participate, when other firms bought them and decided against conducting the planned survey. Once a firm agreed to have our research group administer the survey, we either ran the survey on all or a random sample of employees, with an average response rate of 53\% across the 14 companies. Thus, the survey can be

\footnotetext{
2 Issue 4 included a 100-page article “Cooperation in a Western City” by Albert Shaw about such enterprises in Minneapolis, which examined profit sharing by Charles Pillsbury in his mills and included an interview with Pillsbury. Issue 5 had a 129 page article "Cooperation in the Northeast” by Edward Bemis on Massachusetts companies. In the 1880s a group of doctoral students was assembled at Johns Hopkins University who divided up the United States into regions and studied forms of profit sharing and employee ownership in these regions. The University published these studies as a book (Adams 1888). John Bates Clark worked closely with this group of researchers, several of whose articles appeared in the new journal of the American Economic Association. Clark's views were similar to those of another prominent $19^{\text {th }}$ century economist, John Stuart Mill, who said "The form of association which if mankind continues to improve must be expected in the end to predominate is not that which can exist between a capitalist as chief and workpeople without a voice in the management but the association of the labourers themselves on terms of equality, collectively owning the capital with which they carry on their operations, and working under managers elected and removable by themselves” (John Stuart Mill, Principles of Political Economy, Books III-V and Appendices [1848], in J.M. Robson, ed., Collective Works of John Stuart Mill, Vol. 3. Toronto: University of Toronto Press, 1965, p. 775).
} 
viewed as a random sample of workers from a non-random sample of firms. The survey included core questions common across all companies, and some questions of special interest or relevance to that company. Six company surveys were conducted entirely by web, seven company surveys were done on paper, and one survey was done using both the web and paper surveys. A total of 41,206 respondents provided usable surveys. Appendix A describes the variables used in this analysis.

\section{The Clark vision in modern eyes}

Modern theorists concerned with shared capitalism highlight the potential of corporate culture in helping unify ownership and control with minimal agency costs and enabling shared capitalism to fulfill its potential. In his 2000 address to the Industrial Relations Research Association, Joseph Stiglitz defined the goal of shared capitalism as "to increase each worker's involvement in and identification with the firm so that there will be some unification of agent and principal and a resulting tendency for higher effort... (in the belief that) a system of high involvement, high rewards, and high levels of skill and information, integrated with a corporate strategy that relies on front-line employees' ideas and creativity, is capable of impressive improvements in organizational performance.” Analogously, in their book on incentives, Laffont and Martimort focus on "how the owners of firms succeed in aligning the objectives of various members, such as workers, supervisors, and managers, with profit maximization” (2002, p. 2). They emphasize that the decentralized nature of information and the cluster of transactions between the principal and the agent require an interaction of cultural norms and incentives to obtain the best economic institutions. Presaging our analyses of the importance of worker co-monitoring in shared capitalism (Freeman, Kruse, Blasi, 2007), they stress that the multitude of tasks performed by the worker means that "a worker is not only involved in productive tasks but also must sometimes 
monitor his peers.” In both cases, as well as in the analyses of others ${ }^{3}$, the implication is that shared capitalist compensation needs an appropriate corporate culture to reduce free rider and moral hazard problems and that low intensity incentives that substitute for wages and increase worker risk would have problematic effects on performance.

The other issue that theorists have identified as critical to the working of shared capitalism is the allocation of the risk of ownership and the problem of credit barriers keeping workers from becoming real capitalists. Echoing back to Adam Smith, Stiglitz (1974) argued that the key issue in the use of sharecropping, as opposed to having employees renting capital, is the balance between its incentive effects and risk-sharing features. Though the rental system "has greater incentive effects, it forces the worker to bear all the risks, and although the wage system allows the landlord, if he is risk neutral, to absorb all the risk, it may force heavy supervision costs on him.” He asserted that the end of sharecropping was best explained by the development of capital markets that allow diversification of risk, capital intensity in production, and a faster rate of technological change. These analyses highlight the other distinct aspect of the John Bates Clark solution to the problem: share ownership arising from profit sharing as a way to allow workers to obtain ownership without taking on risk beyond their means. Akerlof's concept of a gift exchange carries this line of thinking a step further, with the exchange of ownership or profit-sharing above fixed pay for reciprocating effort serving as the risk-reducing mechanism for shared capitalism. In the U.S. today, ESOPs, stock options, and company stock matches for contributions to retirement savings plans offer workers ways to get equity in their company without buying it with their savings (though there is a small but growing number of cases in which employees use 401(k) assets to create ESOPs).

\footnotetext{
3 Barnard (1938) defined incentives as involving a package of monetary and non-monetary items saying material incentives were too weak unless enforced by other incentives. Even the bete noir of employee empowerment, Frederick Taylor, argued for paying fair wages along with generous performance-based pay and careful training to keep workers committed to maximum effort, although consultants selling Taylorism dropped this component (Kanigel 1997).
} 
Existing research on shared capitalism has generally found better workplace performance for firms with profit sharing and employee ownership. ${ }^{4}$ However, many of these studies were based on large administrative datasets and shed little light on the mechanisms through which shared capitalism functioned "inside the black box.” Here we use new data to go inside the black box.

\section{Measures of Shared Capitalism}

Were Clark to return to the U.S. in 2006, the first question he would ask about shared capitalism is the extent to which enterprises based on financial sharing and decision-making are found in the market — their "survival ... in comparison with other systems." The GSS provide the best evidence for answering this question. The overall prevalence of shared capitalist compensation is presented in Table A-1, with fuller presentation in the companion paper by Kruse, Blasi, and Park (2008). For our purposes here the most important result is that $45 \%$ of the for-profit private sector employees in the GSS sample report participating in some kind of shared capitalism program (36\% in profit sharing, $25 \%$ in gainsharing, $19 \%$ in employee ownership, and $11 \%$ in stock options), which gives us good variation for examining the relation of these programs to worker outcomes. The prevalence is of course higher in the NBER sample, since these firms were selected on the basis of having these programs.

As a first step in assessing the relation of shared capitalism to employee outcomes, we constructed a thermometer-style index of shared capitalism, which assigns points based on coverage by shared capitalism programs and the size of the financial stakes. This index is described in

\footnotetext{
${ }^{4}$ Evidence from over 60 studies indicates a positive association on average between shared capitalism programs and company performance, but with substantial dispersion in results (see Doucouliagos, 1995, Kruse and Blasi, 1997, and Kruse, 2002, for reviews; also see Black and Lynch, 2001, Boning, Ichniowski, and Shaw, 2001, Core and Guay, 2001, Ittner et al., 2001, Lee, 2003, Robinson and Wilson, 2006, and Sesil et al., 2002). The average estimated increase in productivity associated with employee ownership and profit sharing is about $4.5 \%$, and is maintained when using pre/post comparisons and attempts to control for selection bias.
} 
Appendix B. We also present results breaking out the different forms of shared capitalism types and intensities using the NBER data.

\section{Workplace Outcomes}

We measure six workplace outcomes: 1) turnover (looking for another job vs. staying with the company), 2) absenteeism, 3) workers’ perception of the discretionary effort of co-workers; 4) worker loyalty to the firm, 5) workers' willingness to work hard for the firm 6) the frequency of suggestions to improve efficiency. These outcomes are related to each other-e.g. looking for another job predicts increased absenteeism, as does reduced willingness to provide discretionary effort to the company, and lower loyalty. Reduced willingness to provide discretionary effort to the company and lower loyalty relate to looking harder for another job. Increased absenteeism, looking hard for another job, and lower loyalty are linked to less discretionary effort. Because there are large literatures studying most of these outcomes separately, we decided against forming an index of these variables and instead look at each by itself. The summary statistics in Appendix A show variation in the measures among respondents in our surveys in the form of large standard deviations. The absenteeism variable is the only one with a "peculiar" distribution since many people report zero absences while there is a long tail of persons absent for different time periods.

We use basic multivariate statistics to assess the link between shared capitalist compensation and the outcomes. We estimate OLS models of the impact of shared capitalist compensation on the workplace outcomes where appropriate, and ordered probit models when the outcomes have several values with a natural ordering (e.g., "not at all true, not very true, somewhat true, and very true"). Because more than half of the values of absenteeism are zero, we use the tobit model to analyze that outcome. We run the regressions with the same independent variables for the national and NBER data sets and then probe our results in the NBER data set by adding measures of other human 
resource policies that may independently affect the workplace outcomes, such as participation in an employee involvement team, training, and job security.

We interpret the results from the two surveys differently in light of the difference in their sample designs. Since the GSS is a nationally representative survey, it will have few if any workers in the same firm, so that it provides information on workers across firms. The variation in shared capitalist incentives and behavior reflects differences in firm policies. By contrast, the NBER survey covers a representative sample of workers in a non-representative sample of firms. To deal with the non-representative firm problem, we include company fixed effects in most calculations. This focuses on the effect of variation in shared capitalist incentives on attitudes and behavior within companies. However, we analyze some ESOP variables across companies as well as within companies because ERISA rules require virtually all workers in a firm to be covered, so that the cross-firm variation in the data is potentially more informative than within-firm variation, which may reflect peculiarities between groups of workers within the firm.

Table 1 summarizes the empirical results of regression analyses of the relationship between the shared capitalism index and outcomes in our data sets. It shows that in both the NBER and GSS surveys, the likelihood of searching for another job is lower the higher is the shared capitalism index. When the controls in the national survey and in the NBER survey are the same, the coefficient on the index is the same. Addition of measures of other human resource policies reduces the coefficient in the shared capitalism variable in the NBER data, but it still remains significant (line 2b). In addition, the NBER asked workers if they would turn down a higher-paying job to stay with their firm. The shared capitalist index raises the likelihood that workers would do so (line 3), which implies that they value these policies either for the additional income they are likely to bring or for the stake they give workers in the company. 
The NBER survey asked workers how many days they were absent in the previous six months - a question that was not included on the GSS. Here, the estimate in line 4 of Table 1 shows that the shared capitalism index alone-without looking at the impact of the firm's corporate culture-raises absences. This is the only outcome variable that is adversely associated with the index. Why? Reviewing absenteeism and turnover research, Johns (2002) emphasizes that persistent absenteeism signals a break in the psychological contract of trust and deeper problems in the corporate culture. This perspective sees absenteeism as part of a withdrawal continuum involving lateness-absenteeism-lack of loyalty-intended turnover-ultimate withdrawal of membership in the firm. Thus, the finding that shared capitalism has a different effect on absenteeism than on prospective turnover, loyalty and other factors runs against the basic analysis of absenteeism. Studies of the relation between unionism, which also reduces turnover, however, often also find a positive association with absences. It may be that a greater sense of job security underlies both results. Another possibility is that absenteeism is a form of free riding that avoids co-worker scrutiny and criticism. Yet another possibility, which we explore later, is that the result is related to interactions with other firm policies and corporate culture.

Both the GSS and the NBER surveys ask workers how hard they believe their co-workers work. The estimates show that perceptions of co-worker effort are significantly positively related to the shared capitalism index, though the NBER result is no longer significant after controlling for several human resource policies (lines 5, 7). The NBER survey has two other measures that reflect perceptions of the extent to which co-workers are committed to the firm: the extent to which coworkers have enough interest in company issues to get involved in the firm, and whether coworkers generally encourage each other to make extra efforts. Again, the results show that shared capitalist programs raise the likelihood that workers report positively on these outcomes, both before and after controlling for human resource policies (lines 8-9). 
Interpretation of the positive coefficients of a worker's receipt of shared capitalist compensation in predicting their perceptions of the work attitudes of co-workers is not, however, simple in the presence of the company dummy variables. The regressions reflect how workers paid with shared capitalist compensation view their fellow workers (with a glow) rather than how shared capitalism affects the workplace. Since we have many establishments or facilities within firms, they could also be telling us that facilities with greater shared capitalist compensation have workers who are willing to do more for the firm. One way to deal with this issue is to eliminate the company dummies from the regressions. This strengthens the estimated effects. Another way to deal with the problem is to aggregate the data by facilities so that we relate the average shared capitalism index at a workplace to the average perception of co-worker effort within that worksite. This asks the question most relevant to our analysis: whether respondents perceive greater effort in worksites with more shared capitalism, rather than whether workers with greater personal shared capitalist compensation perceive greater effort in their fellow workers. Figures 1 to 3 display the scatter plot of observations for the site averages and the regression line for them. They show that the shared capitalist index at a worksite is positively associated with workers saying that co-workers give greater effort to the firm.

Finally, we turn from perceptions of how co-workers behave to questions in which workers report on their own attitudes and behavior and relate these responses to the workers' own shared capitalist compensation. Both surveys asked questions relating to worker loyalty. The GSS asked if workers were proud to be working for their employer: shared capitalism raises positive responses on this item (line 6). The NBER asked about loyalty to the firm: this measure is positively related to the shared capitalism index before and after controlling for high-performance policies in the NBER survey (line 10). The NBER survey also asked how willing workers would be to work harder to help the company, and the frequency with which they make suggestions about improving the 
workplace. The higher the shared capitalist index the more likely are workers to say that they themselves would work hard for the firm (line 11), and the more likely are workers to say that they make many suggestions (line 12).

\section{Particular programs}

The NBER survey contains sufficiently detailed information and a large enough sample to allow us to disaggregate the shared capitalist index into its component parts to see which policies or programs contribute more/less to the estimated effects in Table 1. Table 2 gives the results of these calculations for variables in which the individual reports on their own behavior or attitudes. Column 1 shows that the likelihood of not searching for a new job is strongly related to profit sharing and gain sharing eligibility, employee ownership, and having a larger stock option grant last year, and that workers who receive individual bonuses are also less likely to look for another job.

Column 2 shows that the aberrant finding that shared capitalism increases absenteeism is higher among those who are eligible for profit sharing and who hold stock options. This goes against the findings of lower absenteeism in profit sharing companies in UK and French firms (Wilson and Peel, 1991; Brown et al., 1999) and with a study of U.S. firms that found employee ownership alone did not affect absenteeism (Hammer, Landau, and Stern 1981) though it is consistent with the finding by Brown et al. that absenteeism increased slightly when profit sharing was introduced after employee ownership. The regression finding that absenteeism is lower among those who are eligible for individual bonuses lends some support to the possibility that higher absenteeism among those paid by group incentives reflects free rider behavior.

The next two columns show that loyalty and willingness to work hard are positively related to the size of the profit-sharing and gain sharing bonuses, and to holding employer stock purchased through a 401(k) plan or on the open market (cols. 3-4). Loyalty is also positively linked to receiving a stock option grant last year, while willingness to work hard is linked to the size of one's 
ESOP stake. The frequency with which workers report making suggestions is, by contrast, significantly related only to employee ownership (col. 5).

Overall, the forms of shared capitalism that appear to have the strongest effects on outcomes are profit sharing and employee ownership.

The bottom panels in Table 2 disaggregate the ownership variable and report coefficients when the company dummy is removed from the regression. The results for the disaggregation of the shared capitalism index show that the largest ownership impacts come with $401 \mathrm{k}$ plans and when workers buy shares on the open market. The sizable $401 \mathrm{k}$ effect compared to the ESOP ownership effect may reflect the greater individual ownership of the 401k (although the company stock match for which workers do not pay with their savings in 401k plans is comparable to an ESOP) while the impact of buying shares on the open market may reflect individual's positive assessment of the future of the firm. Finally, the regressions that exclude company dummies to pick up differences in shared capitalist compensation across companies as well as across facilities and individuals within facilities find stronger ESOP effects than the regressions that include the company dummy variables.

\section{Complementarities $\rightarrow$ Corporate Culture?}

A critical issue in analysing a distinct organizational or institutional form is whether its impact on behavior and outcomes operates independently of other practices or policies or whether its impact depends interactively on them. The thrust of theoretical analysis of shared capitalist compensation, from Clark to the present, is that changing the monetary incentives by itself is unlikely to occur or work well independent of other policies. Firms that introduce profit sharing or employee ownership must give workers the authority to make decisions that increase performance 
to change their behavior in ways that raise output and profits. ${ }^{5}$ Research on "high performance work systems” have found that they work best as a package of complementary policies regarding recruitment, training/information, performance management/sharing, and work redesign, and so on. ${ }^{6}$ Based on these considerations and evidence we expect that shared capitalist incentives should also work better when combined with other firm policies.

To examine the interaction or complementarity of shared capitalist compensation with highperformance workplace policies, we constructed an index of high-performance work policies that gives one point each for being in an employee involvement team, receiving formal training in the past 12 months, and having high job security. ${ }^{7}$ We interacted this index with the shared capitalism index in regressions for the likelihood of searching for a new job, absenteeism, loyalty to the firm, willingness to work harder, and frequency of suggestions. In addition, we examined the interaction between shared capitalism and a measure of employer supervision of employees. Evidence presented in our companion paper (Kruse, Freeman, and Blasi, 2008) shows that workers covered by more shared capitalist policies are less closely supervised than others, suggesting that shared capitalism substitutes for supervision in motivating workers. Combining shared capitalism with

\footnotetext{
${ }^{5}$ Research often finds an interaction between participation and ownership on output but most data sets contain little information on the mechanisms for this. The General Accounting Office study (1987), which matched survey data with records on company finances, found an interaction between employee participation in management and employee ownership on productivity, as did the U.S. National Institute of Mental Health study (Rosen, Klein, and Young 1986) and its follow up study (Rosen and Quarry 1987). Freeman and Dube (2002) found that employee involvement had a larger impact on indicators of worker productivity, job satisfaction, and attitudes toward the firm than did participation in financial rewards, but that the highest outcomes occurred when firms combined pay for company/group performance, ownership stake in the firm, and employee involvement committees. Analyzing UK establishments, Conyon and Freeman (2001) found that the companies that adopted profit sharing, employee ownership, and broad stock option schemes had higher productivity and more information and decision sharing practices. Studies of ESOPs and other forms of employee ownership generally find a positive relationship between ownership and performance (Levine 1995: 81) that is strongest with worker participation.

${ }^{6}$ Ichniowski et al. 1996; Ichniowski and Shaw 1997; Huselid, Jackson, and Schuler 1997; Becker and Huselid 1998; and Becker, Huselid, and Ulrich 2001. Cappelli and Neumark found that high performance work practices such as selfdirected work teams only significantly predicted increased productivity when combined with profit/gain sharing (1999:34).

7 We experimented with indices that also included measures of information sharing, job rotation, and rigorous selection and obtained similar results. We focus on the index based on employee involvement, training, and job security since the sample sizes are smaller for job rotation and rigorous selection, and the grade of the company on sharing information reflects an employee evaluation of the policy's success rather than the existence of a policy.
} 
close supervision may reduce the effect of shared capitalism by sending a mixed message to employees: "We want you to work harder and be more committed to the company because of your (profit share/employer stock/stock options), but we're still going to keep a close eye on you."

Finally, we also examine whether the extent to which shared capitalism substitutes for fixed wages may also be an important determinant of its effects. We expect that employees will react better to shared capitalist compensation when it is a gift-exchange add-on to existing compensation, rather than a substitute for which they sacrifice certain income flows for greater risk in compensation. While we do not have measures of alternative wages available to employees, the NBER survey asked how employees’ fixed wages compare to market levels, from which we constructed a dummy variable indicating that the worker feels s/he is paid at or above market levels. We interact this variable with the shared capitalist index as well.

Table 3 summarizes the results of these calculations. The regression coefficients on the interaction terms show that other firm policies measured by the high performance practice index affects the impact of shared capitalism—representing possible complementarities on most outcome variables—and that supervision intensity and wage relative to market wage also have some interactive effects. Column 1 shows that the positive effect of shared capitalism on not searching for a new job exists only for those who are covered by the high performance policies and reveals a strong negative interaction of shared capitalism with close supervision. While column 2 finds no significant interactions for any of the three new variables with the shared capitalism index in affecting absenteeism, the high performance indicator reduces absences while close supervision raises them. With these variables and interactions the strong positive relation between shared capitalism and absenteeism is weakened and no longer significantly different from zero, suggesting that the effect found in Table 1 may be masking that of high performance, supervision, and pay 
relative to market. Columns 3 and 4 show substantial shared capitalism interactions on loyalty and willingness to work hard. These outcomes are enhanced when shared capitalism is combined with high performance policies and fixed pay at or above the market level, and are hurt when shared capitalism is combined with close supervision.

Finally, column 5 shows that shared capitalism has a negative interaction with high performance policies and a positive link to supervision in affecting frequency of suggestions. The positive effect of shared capitalist policies among workers who are not covered by high performance policies might reflect the fact that those in high performance work places already have the means and motivation to provide suggestions. One interpretation of the positive interaction with supervision is that shared capitalism provides motivation to closely supervised workers to try to make changes in their work environment to relieve supervisory intensity. Whether these or other explanations account for the observed interactions, the important point is that the interactions are substantial, implying that analyses that treat shared capitalist compensation as a single innovation will invariably miss some of the ways in which it works and the conditions for it to work successfully.

As a graphic demonstration of the importance of the interactions, we show in Figure 4 the relation between workers' likelihood of looking to leave the firm with the shared capitalist index contingent on different values of the interacting variables. ${ }^{8}$ Each line shows how the potential leaving variable changes with shared capitalism given the specified interaction. What is striking is the fanning out of the lines. Shared capitalism increases likely turnover when workers are very closely supervised and are not covered by any high performance policies (top line) — this may

\footnotetext{
8 To enable a more straightforward interpretation, Figure 1 is based not on an ordered probit but on a linear probability regression with the same independent variables as in col. 1 of Table 5 , with the dummy dependent variable taking the value of 1 if a worker said s/he is very likely to look for a new job with another organization or is already looking, and 0 otherwise. This regression closely reflected the pattern of results in Table 5.
} 
reflect workers becoming cynical and wanting to leave when they learn that management espouses a shared capitalism philosophy but still treats them like ordinary employees. In contrast, shared capitalism decreases likely turnover when workers have average or low levels of supervision, or are covered by high performance policies. The strongest effects of shared capitalism are when it is combined with high performance policies and low levels of supervision, causing likely turnover to be cut from $12.8 \%$ to $2.4 \%$ as the shared capitalism index goes from 0 to 10 (bottom line of Figure 4). The average results shown in Table 2 reflect these diverse effects, weighted by the proportion of workers in the various interactive categories.

Finally, we view the interactions shown in Table 3 and Figure 4 as suggesting that the concept of "corporate culture" may provide a useful way to understand the relation between shared capitalism and the workplace outcomes. Analysts sometimes use the corporate culture term loosely without any operational measurement/definition that risks making it a catch-all phrase to describe residuals or puzzles. But when interaction or complementarity effects are demonstrably important, it seems natural to think that some underlying latent variable - corporate culture - may more usefully describe reality than analyses of separate interacting variables.

\section{Worker views}

As an alternative way to assess the impacts of shared capitalist incentives and of their interrelation with other aspects of corporate policy/culture, we asked workers the following hypothetical question on the NBER survey:

To what extent would each of the following affect your motivation to improve the business success of the company? ${ }^{9}$

You receive a cash incentive

The company grants you stock options

You receive some stock in the company ESOP

You can buy some company shares in the ESPP

${ }^{9}$ Employees were asked the stock options, ESOP, and ESPP questions only if the company provided these programs, and were asked the open market purchase questions only if they worked in a public company. 
You buy some company shares in the open market

The upper panel of Table 4 reports the responses to these questions. Close to three-fourths of workers said that their motivation would be improved to a "great" or "very great" extent by receiving a cash incentive (78\%) or stock options (77\%), while about two-thirds of workers said the same about receiving ESOP stock (69\%) or buying shares through an ESPP (63\%), and less than one-third said this about buying company stock on the open market (30\%). This pattern fits well in an analysis of risk in employee response to shared capitalism, with the cash incentive and options being the least risky forms of compensation, and buying shares in the open market placing the workers' capital at greatest risk. The small response to buying shares in the open market conflicts, however, with the significant impacts of that activity on some of the outcome variables in Table 2 .

To see whether worker responses to the hypothetical are influenced by other aspects of company policy/practice, we estimated ordered probit regressions using the variables found to have important interactions with the shared capitalism index in Table 3. The results of these regressions, summarized at the bottom of Table 4, show positive effects of the high performance policy index in four of the five questions (cols. 2-5), supporting the notion of a major complementarity between high performance policies and shared capitalist compensation. Three of the regressions show positive effects of having fixed pay at or above market levels (cols. 2, 4, and 5), likewise supporting a complementarity, but only one regression shows a negative effect of closer supervision (col. 2). The regression that shows a different pattern from all others is the one assessing the effects of receiving a cash incentive (col. 1). In this case, close supervision and perceiving one's pay as below market raises its impact. The positive supervision interaction may be because workers believe that they are more likely to receive the incentive if their supervisor pays close attention to their effort. The stronger effect among those with below-market pay may reflect the view that cash incentives can help make up the perceived pay gap more quickly than by receiving company stock. Finally, 
we note that the ease of seeing how well co-workers work positively affects each response, supporting the idea that an environment of worker co-monitoring is a component in the effectiveness of shared capitalism plans.

\section{Additional issues}

Our analysis cannot rule out some potentially different interpretations of the results. The first is that the findings reflect the selectivity of workers into shared capitalist enterprises rather than or in addition to their response to the way those firms operate. Selectivity could affect the analyses of workers in shared capitalist firms versus others in the GSS survey and would limit generalizing the NBER results to workers who do not work in such firms. Even within a firm, moreover, there may be something special about those who choose greater participation in shared capitalism—for instance, by buying stock through an ESPP or 401(k)—or who management places in positions with more shared capitalist incentives. To get some notion of the possible effects of worker selectivity on our results, we examined the sensitivity of the results to two possible factors that might be associated with self-selection of workers into shared capitalism: a measure of self-rated risk aversion, and family wealth. Neither of these variables made noticeable changes in the relationship of the shared capitalism index either alone or with interactions to the outcomes in Tables 2 and 3.

A second problem relates to the selectivity of firms into our NBER sample and the endogeneity of the decision to offer shared capitalist compensation in both the NBER and GSS samples. Since our NBER results hold constant firm policies and characteristics by comparing workers with greater and lesser shared capitalism in the same firm, we doubt that they are seriously affected by selectivity of firms, but there is the selectivity or endogeneity of the specific policies that the firms have chosen, which still makes causal interpretations of the type we have offered open to criticism. In addition, because the NBER sample does not include firms with no shared capitalist 
arrangements and is based on firms’ willingness to participate, we cannot rule out serious selectivity problems along the firm dimension that might interact with other factors.

Even substantial selectivity among workers or firms, however, does not gainsay the importance of shared capitalist compensation, for it is presumably the interaction between shared capitalist incentives and mode of operating and worker characteristics that underlies the selectivity of workers, and the interaction between other firm policies and their choice of shared capitalist compensation that underlies the selectivity of firms. What selectivity does is weaken our ability to infer what might happen if additional firms adopted shared capitalist arrangements from the successes of existing firms with those practices.

\section{Conclusion}

The principal finding of this paper is that shared capitalism affects workplace performance. The robustness of the finding is increased by the fact that the results from the NBER sample are broadly similar to the results from the nationally-representative GSS. Shared capitalism is linked to lower turnover and greater loyalty and willingness to work hard, particularly when combined with high-performance policies, low levels of supervision, and fixed pay at or above market levels. Workplaces where workers average more shared capitalist compensation report greater employee effort along several dimensions. The only outcome with which shared capitalist compensation is adversely related is absenteeism, but this result largely disappears when controlling for interactions with high performance policies and closeness of supervision.

Looking at particular programs, the strongest effects of shared capitalism are for profit sharing and gain sharing. The largely positive results are corroborated by worker views: most workers report that cash incentives, stock options, ESOP stock, and ESPP participation motivate them to work harder. The less risky forms of shared capitalist programs- profit sharing, gain 
sharing, stock options, and ESOPs - have greater effects than the riskier programs in line with concerns about workers being averse to risking their own capital. (For a closer look at the role of objective and subjective risk in shared capitalism program, see the companion paper by Blasi, Kruse, and Markowitz, 2008.)

Finally, we find important interactions between shared capitalist programs and other aspects of company policies that affect workplace performance. High performance policies are positively linked to good workplace outcomes, and are driven by certain types of shared capitalism. This evidence, combined with our companion paper that finds that shared capitalism increases worker monitoring (Freeman, Kruse, and Blasi 2008), challenges the critique that the motivations of the average worker interfere with the introduction of basic shared capitalism principles. The interaction of the effects of shared capitalism with other corporate policies suggests that the various shared capitalist and other policies may operate through a latent variable, “corporate culture.” Practically speaking, the most important implication of this paper is that shared capitalism and high performance policies appear to work together, with greater impacts when they are combined than when they are used separately. 


\section{APPENDIX A: Variable definitions and descriptive statistics}

\section{COMPENSATION}

Shared capitalism index (GSS): 8-point index with one point each for profit sharing eligibility, gain sharing eligibility, owning any company stock, holding any stock options, receiving a profit sharing bonus in the past year, receiving a gain sharing bonus in the past year, having an above-median profit- and gain sharing bonus as a percent of pay, and having an above-median company stock holding as a percent of pay. Mean=1.48, s.d.=2.14, $\mathrm{n}=1919$

Shared capitalism index (NBER): 10-point index with all items in GS index, plus one point each for receiving a stock option grant in the past year, and having above-median stock option holdings as a percent of pay. Mean=3.60, s.d. $=2.65, n=40522$

Profit sharing (GSS and NBER): "In your job are you eligible for any type of performance-based pay, such as individual or group bonuses, or any type of profit-sharing? What does the size of these performance-based payments depend on? Company profits or performance" (0=no, 1=yes), GSS mean=.372, n=2184, NBER mean=.713, n=41018

Profit sharing as \% of pay (GSS and NBER): If "yes" to profit sharing, answer to "What was the approximate total dollar value of the payment(s) you received [in the most recent year of bonuses]?" divided by basepay+overtime, otherwise 0 . GSS mean=.024, s.d.=.066, $\mathrm{n}=1944$, NBER mean=.068, s.d.=.124, $\mathrm{n}=40485$

Gainsharing (GSS and NBER): "In your job are you eligible for any type of performancebased pay, such as individual or group bonuses, or any type of profit-sharing? What does the size of these performance-based payments depend on? Workgroup or department performance" (0=no, 1=yes), GSS mean=.257, n=2184, NBER mean=.207, $n=41023$

Gainsharing as \% of pay (GSS and NBER): If "yes" to gainsharing, answer to "What was the approximate total dollar value of the payment(s) you received [in the most recent year of bonuses]?" divided by basepay+overtime, otherwise 0 . GSS mean=.017, s.d.=.061, n=2013, NBER mean=.033, s.d. $=.106, \mathrm{n}=40767$

Individual bonus (GSS and NBER): "In your job are you eligible for any type of performance-based pay, such as individual or group bonuses, or any type of profit-sharing? What does the size of these performance-based payments depend on? Individual performance" ( $0=$ no, $1=$ yes). GSS mean=.290, $n=2184$, NBER mean=.290, $n=41019$

Individual bonus as \% of pay (NBER): If "yes" to individual bonus, answer to "What was the approximate total dollar value of the payment(s) you received [in the most recent year of bonuses]?" divided by basepay+overtime, otherwise 0 . Mean=.050, s.d.=.125, n=40547

Hold employer stock (GSS): "Do you own any shares of stock in the company where you now work, either directly or through some type of retirement or stock plan?" ( $0=$ no, $1=y e s)$, mean $=.212, \mathrm{n}=2202$ 
Employer stock as \% of pay (GSS): If "yes" to "hold employer stock," answer to "Please give a general estimate of how much cash you would get if all this stock were sold today?" divided by annual earnings, otherwise 0 , mean $=.111$, s.d. $=.977, \mathrm{n}=2186$

Hold employer stock (NBER): Any employer stock held through ESOP, Employee Stock Purchase Plan, 401(k), exercised stock options, or open market purchases ( $0=$ no, $1=$ yes), mean $=.640, \mathrm{n}=41206$

Employer stock as \% of pay (NBER): If "yes" to "Hold employer stock," the sum of answers to questions about value of stock held in different plans, divided by basepay+overtime, otherwise 0 . NBER mean=.398, s.d. $=.808, \mathrm{n}=40367$

Hold stock options (GSS and NBER): "Do you currently hold any stock options in your company (vested or unvested)?" (0=no, $1=$ yes), GSS mean=.123, n=2188, NBER mean=.219, $\mathrm{n}=41166$.

Stock options as \% of pay (NBER): If "yes" to "Hold stock options," the sum of answers to questions about value of vested and unvested stock, divided by basepay+overtime, otherwise 0 . NBER mean=.395, s.d. $=1.490, \mathrm{n}=40922$

ESOP (NBER): Participant in ESOP (0=no, 1=yes), mean=.081, n=41109

ESOP stock as \% of pay (NBER): Employer stock held in ESOP, divided by basepay+overtime, otherwise 0 , mean $=.067$, s.d. $=.417, \mathrm{n}=41002$

ESPP (NBER): Hold stock purchased through Employee Stock Purchase Plan $(0=$ no, $1=$ yes), mean=.176, $n=41169$

ESPP stock as \% of pay (NBER): Employer stock held in Employee Stock Purchase Plan, divided by basepay+overtime, otherwise 0 , mean=.078, s.d.=.304, $n=41168$

401(k) stock (NBER): Hold employer stock in 401(k) plan (0=no, 1=yes), mean=.335, $n=40885$

401(k) stock as \% of pay (NBER): Employer stock held in 401(k) plan, divided by basepay+overtime, otherwise 0 , mean $=.189$, s.d. $=.525, \mathrm{n}=40730$

Stock from exercised options as \% of pay (NBER): Employer stock held from exercised options, divided by basepay+overtime, otherwise 0 , mean=.052, s.d. $=.396, \mathrm{n}=40956$

Stock from exercised options (NBER): Hold employer stock from exercised options (0=no, $1=$ yes), mean=.050, $\mathrm{n}=41032$

Open mkt. stock as \% of pay (NBER): Employer stock purchased on open market, divided by basepay+overtime, otherwise 0 , mean=.019, s.d. $=.165, \mathrm{n}=41144$

Open mkt. stock (NBER): Hold stock purchased on open market ( $0=$ no, $1=y e s)$, mean $=.073, \mathrm{n}=41145$ 


\section{WORKPLACE PERFORMANCE}

Not likely to search for new job (GSS): "How likely is it that you will decide to look hard for a job with another organization within the next twelve months?" (1-3 scale, Very likely/Somewhat likely/ Not at all likely), mean=2.37, s.d.=.79, n=2400.

Not likely to search for new job (NBER): "How likely is it that you will decide to look hard for a job with another organization within the next twelve months?" (1-4 scale, Already looking/Very likely/Somewhat likely/ Not at all likely), mean=3.42, s.d. $=.83, \mathrm{n}=40722$

Would turn down another job for more pay to stay with this company (NBER): “To what extent do you agree or disagree with this statement? 'I would turn down another job for more pay in order to stay with this company.” (1-5 scale, 1=strongly disagree, 5=strongly agree), mean=1.75, s.d.=1.14, $\mathrm{n}=1175$.

Absenteeism (NBER): "About how many days have you been absent from work in the last 6 months (not counting vacation)?" mean=1.77, s.d.=7.66, $\mathrm{n}=39582$

Co-workers work hard (GSS and NBER): “At your workplace, how hard would you say that people work?” (0-10 scale, $0=$ not at all hard, 10=very hard), GSS mean=6.93, s.d.=2.42, $n=2386$, NBER mean=7.07, s.d. $=2.10, n=40738$.

Proud to be working for employer (GSS): “I am proud to be working for my employer." (1-4 scale, $1=$ strongly disagree, $4=$ strongly agree), mean=3.19, s.d.=.69, $n=2401$.

Co-workers have enough interest in company issues to get involved (NBER): "People at [company] have too little interest in company-wide issues to get involved in them.” (1-7 scale, $1=$ strongly agree, $7=$ strongly disagree), mean=4.22, s.d. $=1.60, \mathrm{n}=40563$.

Co-workers generally encourage each other to make extra effort (NBER): “At your workplace, would you say employees generally ENCOURAGE each other to make an extra effort on the job, DISCOURAGE each other from making an extra effort, or would you say they DON'T CARE how hard other employees work? (-1=discourage, $0=$ don't care, $1=$ encourage), mean=.74, s.d. $=.48, \mathrm{n}=13314$.

Loyalty to company (NBER): "How much loyalty would you say you feel toward the company you work for as a whole?" (1-4 scale, No loyalty at all/ Only a little/Some/ A lot), mean=3.34, s.d. $=.80, \mathrm{n}=40091$

Willing to work harder to help company (NBER): "To what extent do you agree or disagree with this statement? 'I am willing to work harder than I have to in order to help the company I work for succeed?"' (1-5 scale, 1=strongly disagree, 5=strongly agree), mean=4.02, s.d. $=.90, \mathrm{n}=40712$

Frequency of suggestions (NBER): "How often have you taken such ideas [for making your department or company more effective] to someone in the company in the past?" (1=never, $2=$ occasionally, $3=$ monthly, $4=$ =weekly, $5=$ daily), mean=2.21, s.d.=.83, $n=31141$ 


\section{OTHER VARIABLES}

High performance policy index (NBER)(index mean=1.77, s.d.=.86, $n=37125)$ : Additive index of:

a) Employee involvement team: "Some companies have organized workplace decisionmaking in ways to get more employee input and involvement. Are you personally involved in any team, committee or task force that addresses issues such as product quality, cost cutting, productivity, health and safety, or other workplace issues?" (0=no, $1=$ yes), mean=.347, $n=40122$

b) Formal training: "In the last 12 months have you received any formal training from your current employer, such as in classes or seminars sponsored by the employer?" (0=no, $1=$ yes), mean=.564, $n=40460$

c) Job security: "Thinking about the next twelve months, how likely do you think it is that you will lose your job or be laid off?" (coded for scale as $0=$ very likely or fairly likely, $1=$ not too likely or not at all likely), mean=.843, $n=38510$

How closely supervised (NBER): "Are you closely supervised, or do you work fairly independently of close supervision?" (0-10 scale, $0=$ independent of close supervision, $10=$ closely supervised), mean=3.35, s.d. $=2.63, \mathrm{n}=40845$

Fixed pay at or above market (NBER): "Do you believe your fixed annual wages in calendar year 2002 were higher or lower than those of employees with similar experience and job descriptions in other companies in your region?" (rated on scale of $1=$ lower to $5=$ higher, recoded for this variable as $0=$ less than $3,1=3$ or greater), mean $=594, n=35860$

Ease of seeing how well coworker is working (NBER): "In your job how easy is it for you to see whether your co-workers are working well or poorly? Please rate on a scale of 0 to $10 "$ ( $0=$ not at all easy, $10=$ very easy), mean=6.81, s.d. $=2.73, \mathrm{n}=40791$ 


\section{APPENDIX B: The shared capitalist thermometer index}

As a first step in assessing the relation of shared capitalism to employee outcomes, we constructed a thermometer-style index of shared capitalism. This index assigns one point each when the worker was covered by any of the shared capitalist forms of compensation about which the survey asked, with additional points for recent bonuses or grants, and for large bonuses or stock holdings. For questions with a continuous numeric answer, we gave the item a value of 1 if the respondent had a value greater than the median value. Because there is no natural ordering of shared capitalist systems in the sense that a firm first introduces profit-sharing, then adds employee ownership, and then gain-sharing, the index is not a Guttman scale. It is a simple summated rating (Bartholomew et al, 2002; Bartholomew, 1996), using dichotomous scoring.

In the GSS, there are eight variables in the index: profit sharing eligibility, gain sharing eligibility, owning any company stock, holding stock options, receiving a profit sharing bonus in the past year, receiving a gain sharing bonus in the past year, having an above-median profit- and gain sharing bonus as a percent of pay, and having an above-median company stock holding as a percent of pay. In the NBER data there are ten variables in the index: all of the above items plus one point each for receiving a stock option grant in the past year, and having above-median stock option holdings (including unvested options if they could be exercised today) as a percent of pay.

Indices of this style have both advantages and disadvantages. On the plus side, they provide a quick and ready measure of the extent of shared capitalist arrangements that makes it easy to compare results across surveys and to summarize the broad thrust of findings. Since our firm surveys covered only firms with some shared capitalist arrangements, the index allows us to differentiate workers with differing degrees of incentive to their firm's programs. On the negative side, the index treats different programs the same even though they potentially have different effects on particular outcomes. It postulates a single scale with equal weights rather than using factor 
analysis or other statistical modelling to obtain weights for given factors. To deal with these problems, in Table 2 we also estimated the relationship of the outcomes to the different types of shared capitalism, introduced as dummy or continuous variables in regressions. ${ }^{10}$ By comparing the results using the shared capitalism index to the results using the disaggregated measures, we can assess the loss of information due to the amalgamation of the measures into a single index.

Figure B1 shows the distribution of our shared capitalism index in the GSS. This survey estimates that $40 \%$ of US workers have some form of shared capitalist program. This estimate is close to that obtained by Dube and Freeman in the WRPS. The mean score of the index is 1.48 - a figure greatly affected by the substantial number of workers without shared capitalism systems. Conditional on having a program, most workers report scores in the range of 2 to 5 , with 6\% reporting scores of 6 or greater. Figure B2 gives the distribution of the index in the NBER survey data. It also shows a non-normal distribution, with the most common scores as 2 to 4 but a sizeable number of workers scoring 7 or above. There is sufficient variation in the index to differentiate the extent of the shared capitalist "treatment" on workers.

\footnotetext{
${ }^{10}$ There are statistical techniques to deal with the formation of latent variable indices from questions of the sort that we are amalgamating into a single summated rating. See Bartholomew et al. (2002) and Spector (1992).
} 


\section{BIBLIOGRAPHY}

Adams, Henry B. 1888. History of Cooperation in the United States. Baltimore: Hopkins Hopkins University and N. Murray.

Bartholomew, David. 1996. The Statistical Approach to Social Measurement. San Diego: Academic Press.

Bartholomew, David, J. Galbraith, Irini Moustkaki, Fionay Steele. 2002. The Analysis and Interpretation of Multivariate Data for Social Scientists. Chapman and Hall/CRC.

Becker, Brian E. and Mark A. Huselid. 1998. "High Performance Work Systems and Firm Performance: A Synthesis of Research and Managerial Implications,” in Research in Personnel and Human Resources, G. Ferris, Ed, Vol 16, Greenwich, Connecticut.: JAI Press.

Becker, Brian E., and Mark A. Huselid, and Dave Ulrich. 2001. The HR Scorecard: Linking People, Strategy, and Performance. Cambridge: Harvard Business School Press,

Bemis, Edward W. 1886. "Cooperation in The Northeast," Publications of the American Economic Association, Vol. 1, No. 5. (November, 1886), pp. 7-136.

Black, Sandra E., and Lisa N. Lynch. 2000. "What's Driving the New Economy: The Benefits of Workplace Innovation.” Cambridge, Mass.: NBER Working Paper No. W7479, January.

Blasi, Joseph, Michael Conte and Douglas Kruse. 1996. "Employee Ownership and Corporate Performance Among Public Corporations,” Industrial and Labor Relations Review, Vol. 50, No. 1, October, pp. 60-79.

Blasi, Joseph, Douglas Kruse, and Aaron Bernstein. 2003. In the Company of Owners. New York: Basic Books.

Blasi, Joseph, Douglas Kruse, and Harry M. Markowitz. 2008. "Risk and Lack of Diversification under Employee Ownership and Shared Capitalism. ” Presented at NBER/Russell Sage Foundation conference, New York, NY, October 2006.

Blinder, A.S. ed. Paying for Productivity: A Look at the Evidence. Washington, D.C.: Brookings Institution.

Bonin, J.P., and Louis Putterman. 1987. Economics of Cooperation and the Labor-Managed Economy. New York: Harwood Academic Publishers.

Boning, Brent, Casey Ichniowski, and Kathryn Shaw. 2001. "Opportunity Counts: Teams and the Effectiveness of Production Incentives," National Bureau of Economic Research Working Paper 8306. 
Buchele, Robert, Douglas Kruse, Loren Rodgers, and Adria Scharf. 2008. "Show Me the Money: The Wealth Impact of Shared Capitalism.” Presented at NBER/Russell Sage Foundation conference, New York, NY, October 2006.

Budd, John. 2008. "Does Employee Ignorance Undermine Shared Capitalism” Presented at NBER/Russell Sage Foundation conference, New York, NY, October 2006.

Cappelli, Peter, and David Neumark. 2001. "Do "High-Performance" Work Practices Improve Establishment-Level Outcomes?” Industrial and Labor Relations Review, Volume 54, Number 4, July.

Carberry, Edward. 2008. "An Analysis of Social Stratification in Companies with Shared Capitalism.” Presented at NBER/Russell Sage Foundation conference, New York, NY, October 2006.

Clark, John Bates. 1886. The Philosophy of Wealth. Boston: Ginn \& Company.

Conyon, Martin and R. Freeman. 2001. "Shared Modes of Compensation and Firm Performance: UK Evidence." Working Paper Number 8488. National Bureau of Economic Research.

Core, John E., and Wayne R. Guay. 2001. "Stock Option Plans for Non-executive Employees,” Journal of Financial Economics, Volume 61, pps. 2532-287.

Craig B. and J. Pencavel. 1992. "The Behavior of Worker Cooperatives: The Plywood Companies of The Pacific Northwest," American Economic Review, 82, 1083-1105.

-----. 1993. "The Objectives of Worker Cooperatives," Journal of Comparative Economics, Vol. 17(2), June, pp. 288-308.

-----. 1995. "Participation and Productivity: A Comparison of Worker Cooperatives and Conventional Firms in The Plywood Industry," Brookings Papers on Economic Activity, 212-160.

Doucouliagos, Chris. 1995. "Worker Participation and Productivity in Labor-managed and Participatorry Capitalist Firms: A Meta-analysis,” Industrial and Labor Relations Review, Vol. 49, No. 1, October, pp. 58-77.

Eliot, Charles W. 1917. “The Road to Industrial Peace,” The Nation’s Business, August, p. 17.

Estrin, Saul, and Derek C. Jones. 1992. "The Viability of Employee-Owned Firms: Evidence from France," Industrial \& Labor Relations Review, Vol. 45 (2). p 323-38, January.

FitzRoy, Felix R., and Kornelius Kraft. 1987. "Cooperation, Productivity, and Profit Sharing." Quarterly Journal of Economics, Vol. 102, No. 1 (February), pp. 23-35.

Fudenberg, Drew, Eric Maskin. 1986. "The Folk Theorem in Repeated Games with Discounting or with Incomplete Information." Econometrica, Vol. 54, No. 3 (May), pp. 533-54. 
Freeman, Richard, and Arindrajit Dube. 2000. "Shared Compensation and Decision-making in the U.S. Job Market.” Cambridge, Massachusetts: Harvard University Department of Economics and National Bureau of Economic Research.

Freeman, R and Joel Rogers. 1999. What Workers Want. New York: Russell Sage and Cornell University Press.

Freeman, Richard, Douglas Kruse and Joseph Blasi. 2008. "Worker Responses to Shirking Under Shared Capitalism.” Presented at NBER/Russell Sage Foundation conference, New York, NY, October 2006.

Hammer, T. H., Landau, J., and Stern, R. N. 1981. “Absenteeism When Workers Have a Voice: The Case of Employee Ownership,” Journal of Applied Psychology, 1981, 66, pp. 561-573.

Heneman, Robert L, and Charles R. Fay, and Zhong-Ming Wang. 2002. “Compensation Systems in the Global Context,” in Handbook of Industrial, Work, and Organizational Psychology, ed Neil Anderson, Deniz S. Ones, Handan Kepir Sinnangil. Thousand Oaks, Ca.: Sage.

Huselid, Mark, and Susan Jackson, and Randall Schuler. 1997. “Technical and Strategic Human Resource Management Effectiveness as Determinants of Firm Performance,” Academy of Management Journal, Volume 40, Number 1, pps. 171-188.

Ichniowski, Casey, Thomas Kochan, David Levine, Craig Olson, and George Strauss. 1996. "What Works at Work: Overview and Assessment," Industrial Relations, 35(3) 299-333.

Ichniowski, Casey, Kathryn Shaw, and Giovanna Prennushi. 1997. "The Effects of Human Resource Management Practices on Productivity: A Study of Steel Finishing Lines," American Economic Review, 87 (3), pp. 291-313.

Johns, Gary, 2002. “The Psychology of Lateness, Absenteeism, and Turnover.” In Neil Anderson, Deniz S. Ones, and Handan Kepir Sinnangil, eds., Handbook of Industrial, Work, and Organizational Psychology. Thousand Oaks, Ca.: Sage.

Judge, Timothy A., Sharon K. Parker, Amy E. Colbert, Daniel Heller, and Remus Ilies. "Job Satisfaction: A Cross-cultural Review.” In Neil Anderson, Deniz S. Ones, and Handan Kepir Sinnangi, Handbook of Industrial, Work, and Organizational Psychology. Thousand Oaks, Ca.: Sage.

Kandel, Eugene, and Edward P. Lazear. 1992. "Peer Pressure and Partnerships." Journal of Political Economy, Vol. 100, No. 4 (August), pp. 801-17.

Kanigel, Robert. 1997. The One Best Way: Frederick Winslow Taylor and the Enigma of Efficiency. NY: Viking.

Kruse, Douglas. 1993. Profit Sharing: Does It Make A Difference? Kalamazoo, MI: W.E. Upjohn Institute for Employment Research. 
-----. 2002. "Research Evidence on Prevalence and Effects of Employee Ownership,” Testimony before the Subcommittee on Employer-Employee Relations, Committee on Education and the Workforce, U.S. House of Representatives, February 13.

-----, and Joseph Blasi. 1997. "Employee Ownership, Employee Attitudes, and Firm Performance: A Review of the Evidence." In David Lewin, Daniel J.B. Mitchell, and Mahmood A. Zaidi, eds., Human Resources Management Handbook, Part 1. Greenwich, CT.: JAI Press.

Kruse, Douglas, Joseph Blasi, and Rhokeun Park. 2008. "Shared Capitalism in the U.S. Economy: Prevalence, Characteristics, and Employee Views of Financial Participation in Enterprises." Presented at NBER/Russell Sage Foundation conference, New York, NY, October 2006.

Kruse, Douglas, Richard Freeman, and Joseph Blasi. 2008. "Do Workers Gain by Sharing? Employee Outcomes Under Employee Ownership, Profit Sharing, and Broad-based Stock Options.” Presented at NBER/Russell Sage Foundation conference, New York, NY, October 2006.

Laffont, Jean-Jacques, and David Martimort. 2002. The Theory of Incentives: The Principal-Agent Model. Princeton, N.J.: Princeton University Press.

Ittner, Christopher, and Richard Lambert, and David Larcker. The Structure and Performance Consequences Of Equity Grants To Employees Of New Economy Companies. Philadelphia, Pa. : University of Pennsylvania, Wharton School of Business, January 2001

Lee, Ya-Ting. 2003. “The Productivity Effects of Employee Stock Ownership Plans: Evidence from Panel Data of Taiwan Electronic Companies,” International Journal of Management, Vol. 20, No. 4, December, pp. 279-289.

Levine, David I. 1995. Reinventing the Workplace: How Business and Employees Can Both Win. Washington, D.C.: Brooking Institution

Quarrey, M., \& Rosen, C. 1993. Employee Ownership and Corporate Performance. Oakland, CA: National Center for Employee Ownership.

Robinson, Andrew, and Nicholas Wilson. 2006. "Employee Financial Participation and Productivity: An Empirical Reappraisal,” British Journal of Industrial Relations, Vol. 44, No. 1, March, pp. 31-50.

Rosen, Corey, and Michael Quarrey. 1987. “How Well Is Employee Ownership Working,” Harvard Business Review, Volume 65, September-October, pps. 126-130.

Rosen, Corey, and Katherine Klein, and Karen M. Young., 1986. Employee Ownership in America: The Equity Solution. Lexington, Ma.: D.C. Heath, Lexington Books.

Sesil, James, and Maya Kroumova, and Joseph Blasi, and Douglas Kruse. 2002. "Broad-based Employee Stock Options in U.S. New Economy Firms," British Journal of Industrial Relations, Volume 4, Number 2, June, pps. 273-294 
Shaw, Albert. 1886. “Cooperation in a Western City,” Publications of the American Economic Association, Vol. 1, No. 4. (September), pp. 7-106.

Smith, A. 1776. The Wealth of Nations. New York: The Modern Library.

Stiglitz, Joseph E. 2002. "Democratic Developments As The Fruits of Labor.” Keynote Address, Industrial Relations Research Association, Boston.

-----. 1974. “Incentives and Risk Sharing in Sharecropping,” The Review of Economic Studies. Volume 4, Issue 2, April, pps. 219-255.

U.S. General Accounting Office (GAO). 1987. Employee Stock Ownership Plans. Washington, D.C.: U.S. General Accounting Office, October, GAO/PEMD-88-1.

Weitzman, Martin L. 1984. The Share Economy. Cambridge, MA: Harvard University Press.

-----, and Douglas Kruse. 1990. "Profit Sharing and Productivity,” in Alan Blinder, ed., Paying For Productivity: A Look at the Evidence. Washington, D.C.: Brookings Institution. 


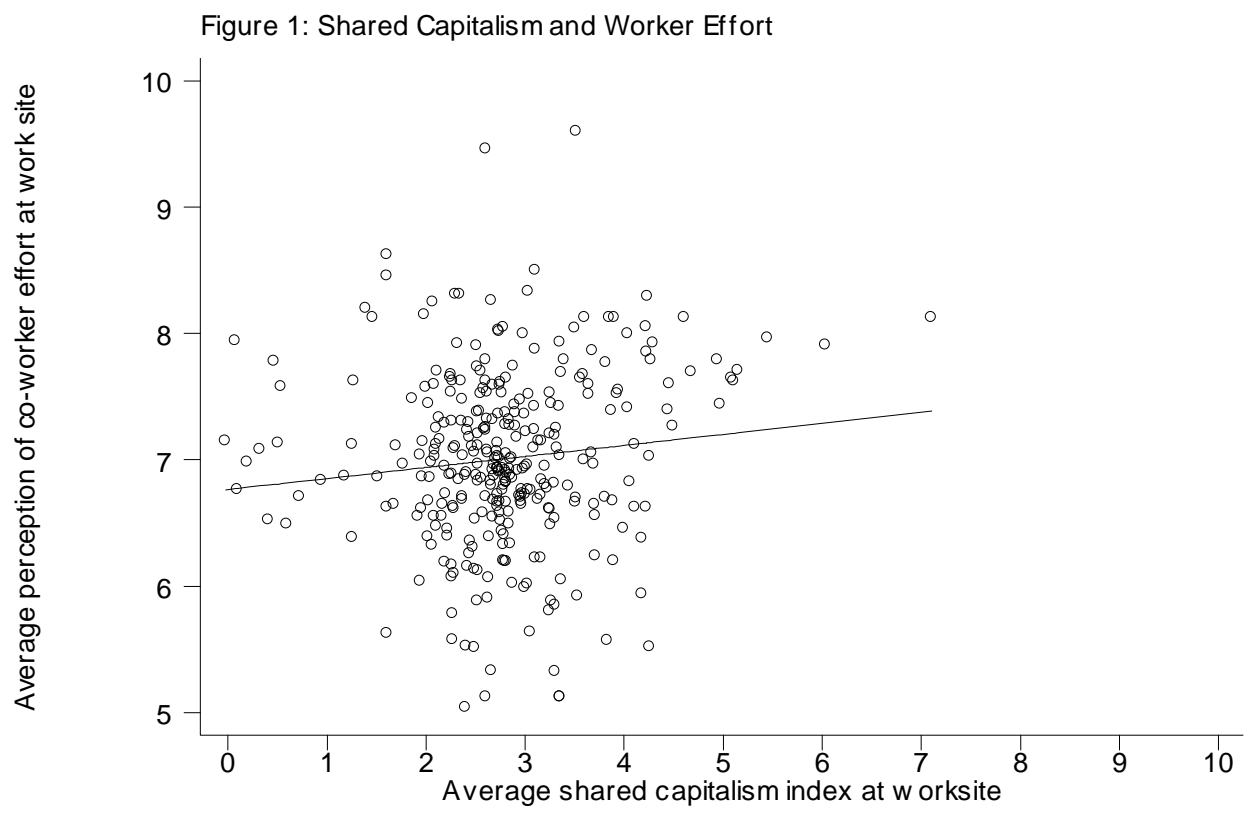

Co-workers work hard $(1-10$ scale $)=6.765+0.087$ (shared capitalist index) (.125) (.043)

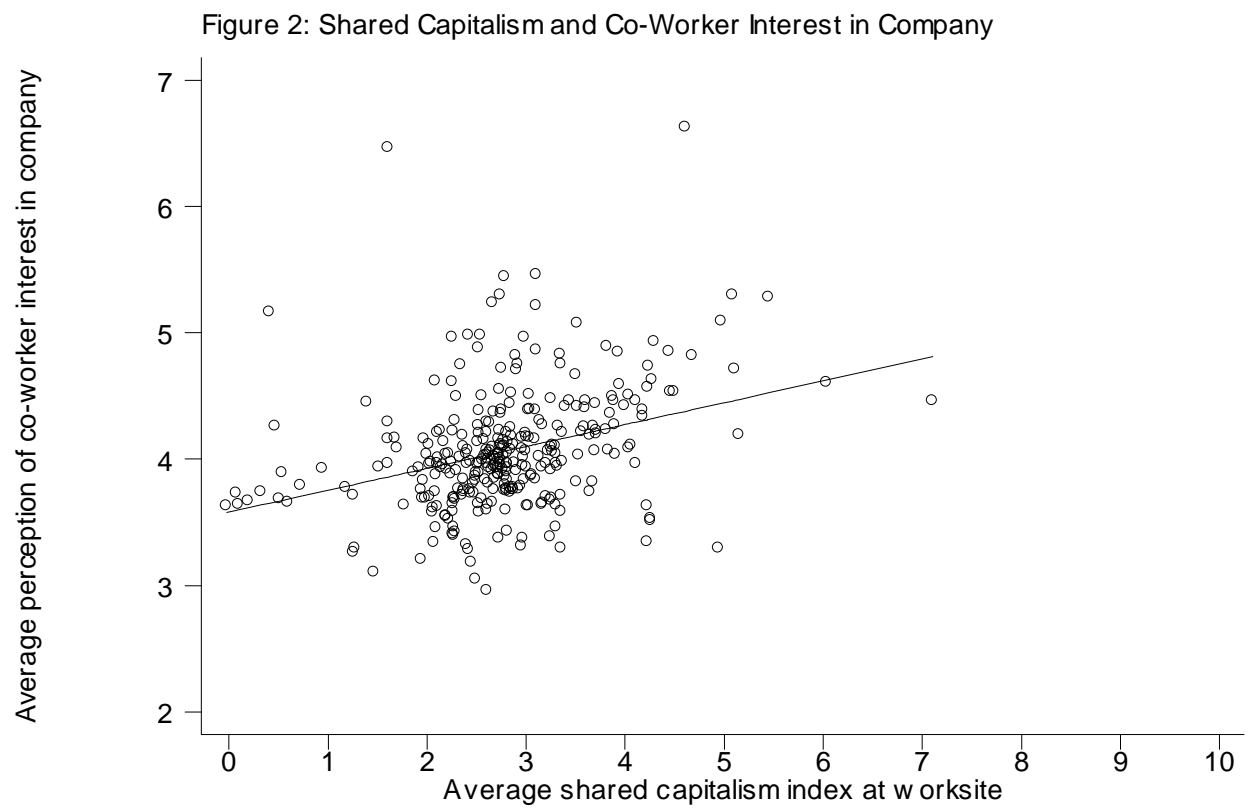

Co-workers work interest in firm $(1-10$ scale $)=3.580+0.173$ (shared capitalist index) (.082) (.028) 


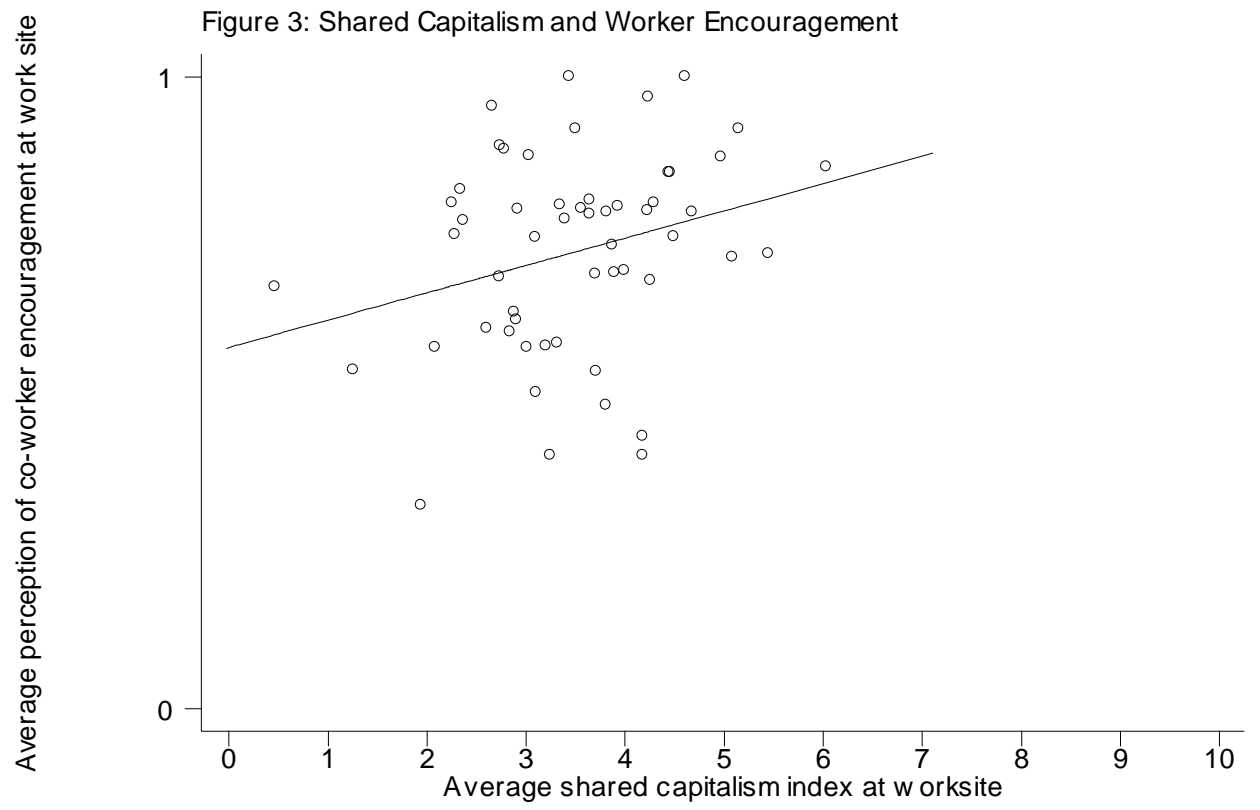

Co-workers encourage others $(1-10$ scale $)=0.572+0.043$ (shared capitalist index) (.073) (.020) 
Figure 4: Contingent Effects of Shared Capitalism on Likely Turnover

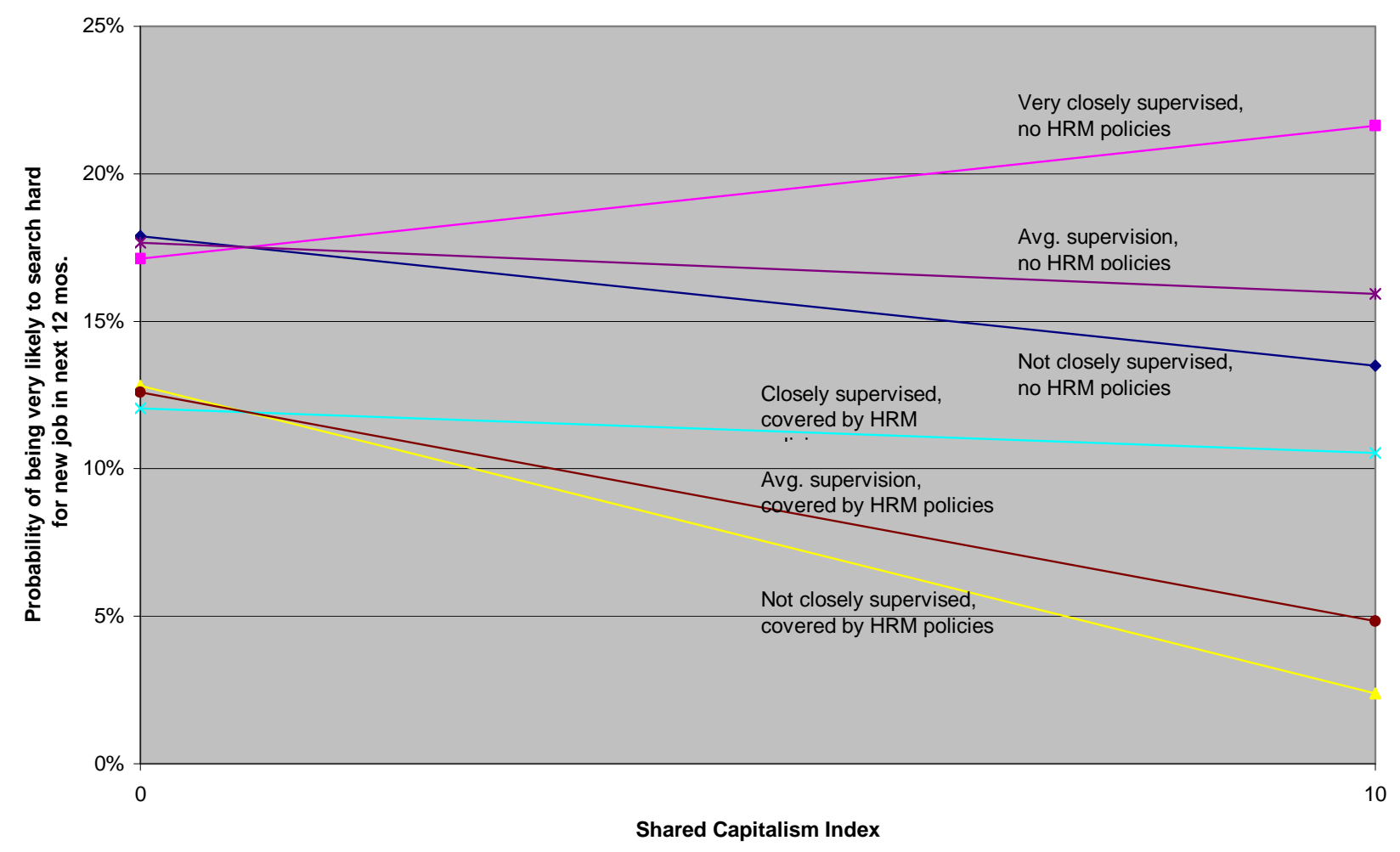


Figure B1: Distribution of Shared Capitalism Index in GSS

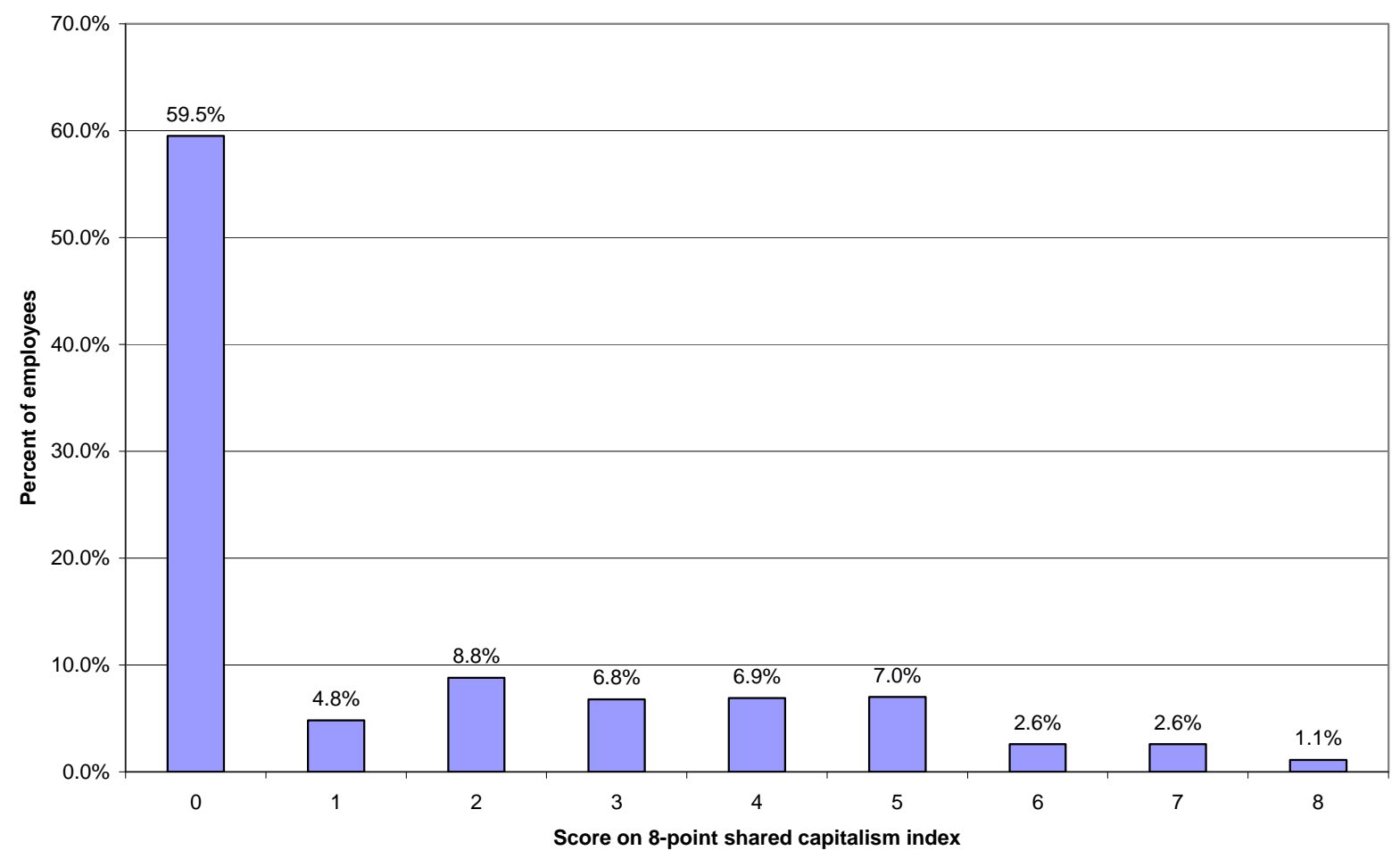

Figure B2: Distribution of Shared Capitalism Index in NBER Companies

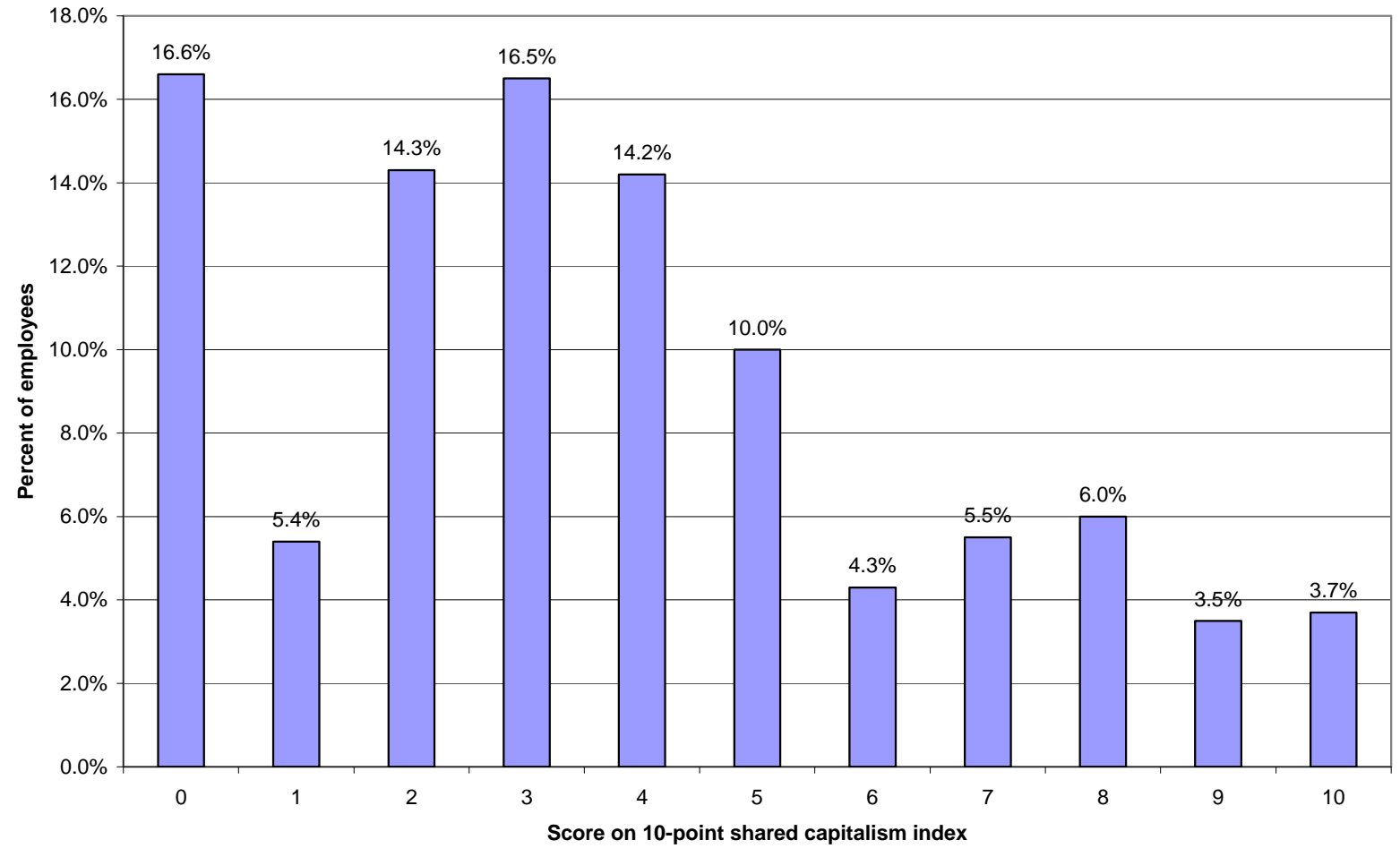


TABLE 1: Relation of Shared Capitalism to Workplace Outcomes

Each row represents results of separate regression.

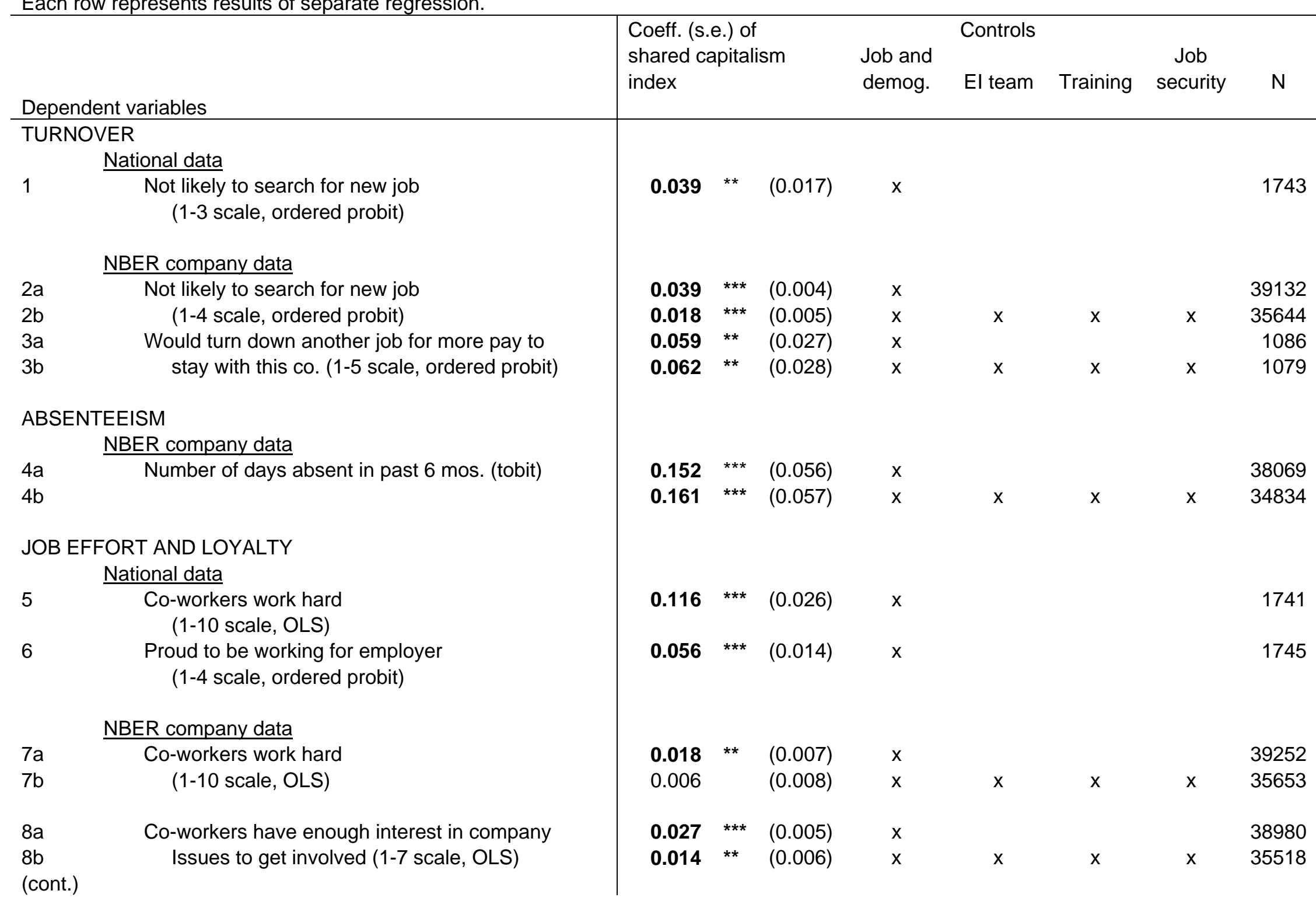




\begin{tabular}{|c|c|c|c|c|c|c|c|c|c|}
\hline $9 a$ & Co-workers generally encourage each other to & 0.038 & *** & $(0.008)$ & $x$ & & & & 12799 \\
\hline $9 b$ & make extra effort (0-1, OLS) & 0.029 & *** & $(0.009)$ & $\mathrm{x}$ & $\mathrm{x}$ & $\mathrm{x}$ & $x$ & 12537 \\
\hline $10 a$ & Loyalty toward co. & 0.041 & *** & $(0.004)$ & $x$ & & & & 38514 \\
\hline $10 b$ & (1-4 scale, ordered probit) & 0.021 & *** & $(0.005)$ & $x$ & $x$ & $\mathrm{x}$ & $x$ & 35082 \\
\hline $11 a$ & Willing to work harder to help co. & 0.023 & *** & $(0.004)$ & $\mathrm{x}$ & & & & 39159 \\
\hline 11b & (1-5 scale, ordered probit) & 0.015 & *** & $(0.004)$ & $x$ & $x$ & $\mathrm{x}$ & $x$ & 35595 \\
\hline $12 \mathrm{a}$ & Frequency of suggestions & 0.035 & *** & $(0.005)$ & $\mathrm{x}$ & & & & 29965 \\
\hline $12 \mathrm{~b}$ & (1-5 scale, ordered probit) & 0.027 & *** & $(0.005)$ & $\mathrm{x}$ & $\mathrm{x}$ & $x$ & $x$ & 26860 \\
\hline
\end{tabular}

$* p<.10 * * p<.05 * * * p<.01 \quad$ Coefficients in bold are significant at $p<.05$

See Appendix A for variable definitions and descriptive statistics.

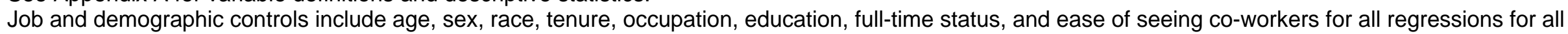

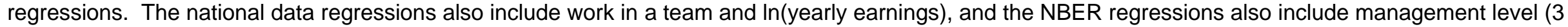
dummies), supervisory status, union membership, disability status, payment on an hourly rate, country effects (21 dummies), closeness of supervision, In(base pay), and company fixed effects. 
Table 2: Workplace Outcomes Related to Type of Shared Capitalism Plan

\begin{tabular}{|c|c|c|c|c|c|c|c|c|c|c|c|c|c|c|c|}
\hline Bonuses & \multicolumn{3}{|c|}{$\begin{array}{l}\text { Not likely to } \\
\text { search for new job } \\
\text { (ordered } \\
\text { probit) } \\
\quad(1)\end{array}$} & \multicolumn{3}{|c|}{ Absenteeism } & \multicolumn{2}{|l|}{$\begin{array}{l}\text { Loyalty } \\
\text { (ordered } \\
\text { probit) } \\
\qquad(3)\end{array}$} & & \multicolumn{2}{|c|}{$\begin{array}{l}\text { Willing to } \\
\text { work harder } \\
\text { (ordered } \\
\text { probit) } \\
\quad(4)\end{array}$} & & \multicolumn{2}{|c|}{$\begin{array}{l}\text { Suggestion } \\
\text { frequency } \\
\text { (ordered } \\
\text { probit) } \\
\quad(5)\end{array}$} & \\
\hline Profit sharing & 0.096 & $(0.021)$ & $\star \star * *$ & 0.929 & $(0.268)$ & $\star \star * *$ & 0.011 & $(0.021)$ & & 0.039 & $(0.019)$ & $\star \star$ & 0.034 & $(0.023)$ & \\
\hline Gainsharing & 0.085 & $(0.028)$ & $\star \star \star *$ & 0.489 & $(0.360)$ & & 0.015 & $(0.028)$ & & 0.034 & $(0.026)$ & & 0.021 & $(0.034)$ & \\
\hline Gainsharing bonus as $\%$ of base pay & 0.095 & $(0.114)$ & & -4.117 & $(1.559)$ & *** & 0.203 & $(0.123)$ & & 0.266 & $(0.109)$ & $\star *$ & -0.114 & $(0.199)$ & \\
\hline Individual bonus & 0.082 & $(0.027)$ & $* \star *$ & -0.975 & $(0.342)$ & *** & 0.143 & $(0.027)$ & $\star \star \star *$ & 0.063 & $(0.025)$ & $\star \star \star *$ & 0.004 & $(0.032)$ & \\
\hline Indiv. bonus as $\%$ of base pay & 0.012 & $(0.117)$ & & -0.364 & $(1.602)$ & & -0.100 & $(0.124)$ & & 0.128 & $(0.111)$ & & 0.152 & $(0.188)$ & \\
\hline \multicolumn{16}{|l|}{ Stock options } \\
\hline Stock option holding & 0.111 & $(0.059)$ & * & 1.583 & $(0.715)$ & ** & -0.140 & $(0.058)$ & $\star *$ & -0.085 & $(0.053)$ & & -0.021 & $(0.070)$ & \\
\hline Rec'd stock option grant last year & -0.074 & $(0.058)$ & & -0.633 & $(0.699)$ & & 0.187 & $(0.057)$ & $\star \star *$ & 0.034 & $(0.052)$ & & 0.028 & $(0.071)$ & \\
\hline Stock option grant as \% of avg. grant & 0.037 & $(0.014)$ & $\star \star \star *$ & 0.175 & $(0.165)$ & & 0.016 & $(0.014)$ & & 0.009 & $(0.012)$ & & -0.032 & $(0.020)$ & \\
\hline \multicolumn{16}{|l|}{ Employee ownership } \\
\hline Any employee ownership & 0.072 & $(0.020)$ & $* * *$ & 0.347 & $(0.248)$ & & 0.065 & $(0.019)$ & $\star \star \star *$ & 0.015 & $(0.018)$ & & 0.166 & $(0.021)$ & *** \\
\hline Employee-owned stock as \% of pay & 0.001 & $(0.010)$ & & -0.171 & $(0.127)$ & & 0.051 & $(0.010)$ & $\star \star * *$ & 0.008 & $(0.009)$ & & 0.024 & $(0.014)$ & * \\
\hline $\mathrm{n}$ & 37796 & & & 36769 & & & 37192 & & & 37817 & & & 29292 & & \\
\hline (pseudo) R-sq. & 0.035 & & & 0.018 & & & 0.060 & & & 0.042 & & & 0.074 & & \\
\hline Cut point 1 & -0.826 & $(0.239)$ & & & & & -0.578 & $(0.246)$ & & -0.858 & $(0.226)$ & & 1.327 & $(0.313)$ & \\
\hline Cut point 2 & -0.318 & $(0.239)$ & & & & & 0.226 & $(0.246)$ & & -0.318 & $(0.226)$ & & 3.560 & $(0.313)$ & \\
\hline Cut point 3 & 0.640 & $(0.239)$ & & & & & 1.381 & $(0.246)$ & & 0.627 & $(0.226)$ & & 4.117 & $(0.313)$ & \\
\hline Cut point 4 & & & & & & & & & & 1.864 & $(0.226)$ & & 4.826 & $(0.314)$ & \\
\hline \multicolumn{16}{|l|}{$\begin{array}{l}\text { Breakdowns by type of employee } \\
\text { ownership^ }\end{array}$} \\
\hline
\end{tabular}




\begin{tabular}{|c|c|c|c|c|c|c|c|c|c|c|c|c|c|c|c|}
\hline ESPP & -0.013 & $(0.042)$ & & 0.780 & $(0.518)$ & & 0.047 & $(0.043)$ & & 0.058 & $(0.039)$ & & -0.039 & $(0.068)$ & \multirow[b]{3}{*}{$\star * \star$} \\
\hline ESPP stock as \% of pay & 0.063 & $(0.035)$ & * & -0.519 & $(0.441)$ & & 0.053 & $(0.036)$ & & 0.029 & $(0.031)$ & \multirow{3}{*}{ *** } & -0.094 & $(0.114)$ & \\
\hline 401(k) stock & 0.105 & $(0.019)$ & 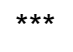 & 0.118 & $(0.230)$ & & 0.111 & $(0.018)$ & 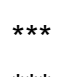 & 0.072 & $(0.017)$ & & 0.115 & $(0.020)$ & \\
\hline $401(k)$ stock as $\%$ of pay & 0.031 & $(0.017)$ & * & -0.180 & $(0.213)$ & & 0.087 & $(0.016)$ & \multirow[t]{2}{*}{$* \star \star$} & -0.011 & $(0.015)$ & & -0.003 & $(0.021)$ & \\
\hline Stock from options & -0.032 & $(0.040)$ & & 0.810 & $(0.503)$ & & 0.061 & $(0.043)$ & & -0.002 & $(0.038)$ & & -0.012 & $(0.069)$ & \multirow{4}{*}{$\begin{array}{l}\star * * \\
\star * \\
\end{array}$} \\
\hline Stock from options as \% of pay & -0.040 & $(0.021)$ & * & -0.176 & $(0.286)$ & & 0.019 & $(0.024)$ & \multirow{3}{*}{ *** } & -0.001 & $(0.021)$ & & 0.047 & $(0.073)$ & \\
\hline Open mkt. stock & -0.018 & $(0.029)$ & & -1.146 & $(0.399)$ & 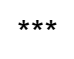 & 0.089 & $(0.031)$ & & 0.072 & $(0.028)$ & ** & 0.160 & $(0.052)$ & \\
\hline Open mkt. stock as \% of pay & 0.010 & $(0.049)$ & & 0.300 & $(0.625)$ & & -0.031 & $(0.052)$ & & 0.035 & $(0.048)$ & & -0.515 & $(0.255)$ & \\
\hline \multicolumn{16}{|l|}{ SOP coefficients without fixed effects' } \\
\hline ESOP & 0.168 & (0.035) & $* * \star$ & -0.190 & $(0.422)$ & & 0.186 & (0.034) & $\star \star \star *$ & -0.001 & $(0.032)$ & & -0.080 & & \multirow[t]{2}{*}{ ** } \\
\hline ESOP stock as \% of pay & -0.021 & $(0.020)$ & & -0.170 & $(0.242)$ & & 0.017 & $(0.020)$ & & 0.051 & $(0.018)$ & $\star \star \star *$ & 0.037 & $(0.023)$ & \\
\hline
\end{tabular}

${ }^{\star} p<.10{ }^{* *} p<.05{ }^{\star * \star} p<.01$ (s.e. in parentheses)

See Appendix A for variable definitions and descriptive statistics.

All regressions include controls for occupation ( 5 dummies), mgt. level (3 dummies), hourly pay status, supervisory status, tenure in years, hours worked per week, union status, age, gender, marital status (2 dummies), family size, college graduate, graduate degree, number of kids, race (4 dummies), disability status, In(fixed pay), closeness of supervision, ability to observe co-workers, country effects (21 dummies), and company fixed effects.

$\wedge$ The sections labelled "Breakdown by type of employee ownership" and "ESOP coefficients without fixed effects" represent separate regressions which contain all of the bonus and stock option variables listed above, along with the control variables listed below. 
Table 3: Interactions between Company Policies and Workplace Outcomes

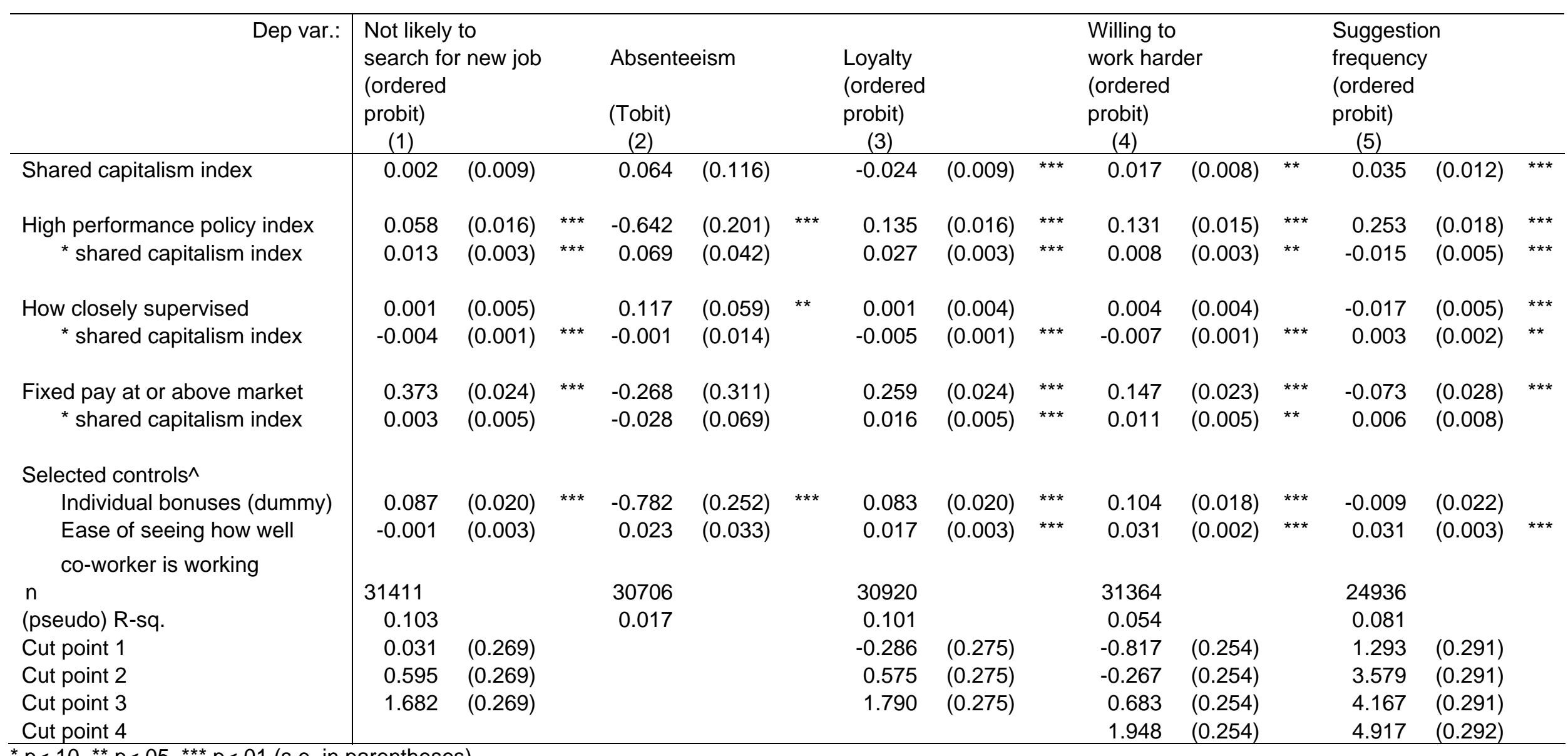

${ }^{*} p<.10{ }^{* \star} p<.05{ }^{* \star *} p<.01$ (s.e. in parentheses)

See Appendix A for variable definitions and descriptive statistics.

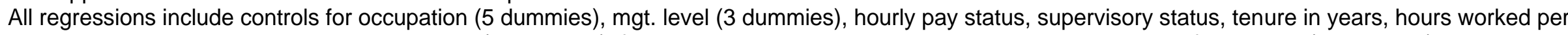

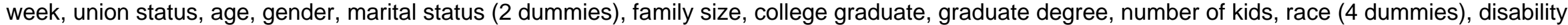
status, In(fixed pay), closeness of supervision, ability to observe co-workers, country effects (21 dummies), and company fixed effects. 
Table 4: Employee Views of the Impact of Shared Capitalist Incentives on their behavior

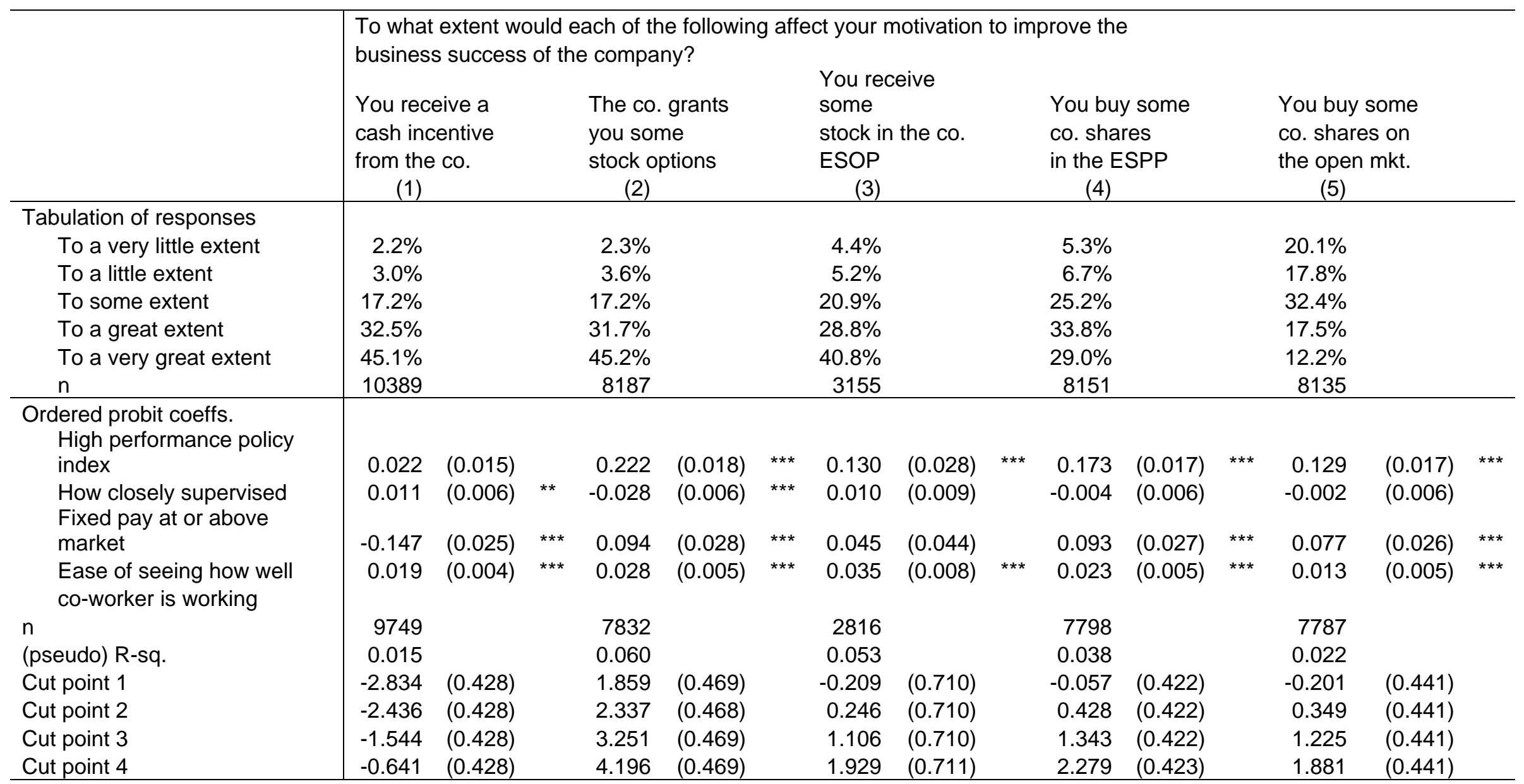

* $p<.10 * * p<.05 * * \star p<.01$ (s.e. in parentheses)

$\wedge$ All regressions include controls for occupation (5 dummies), mgt. level (3 dummies), hourly pay status, supervisory status, tenure in years, hours worked per week, union status, age, gender, marital status (2 dummies), family size, college graduate, graduate degree, number of kids, country (21 dummies), race (4 dummies), disability status, In(fixed pay), and company fixed effects. 
Table A-1: Prevalence of Shared Capitalism Programs

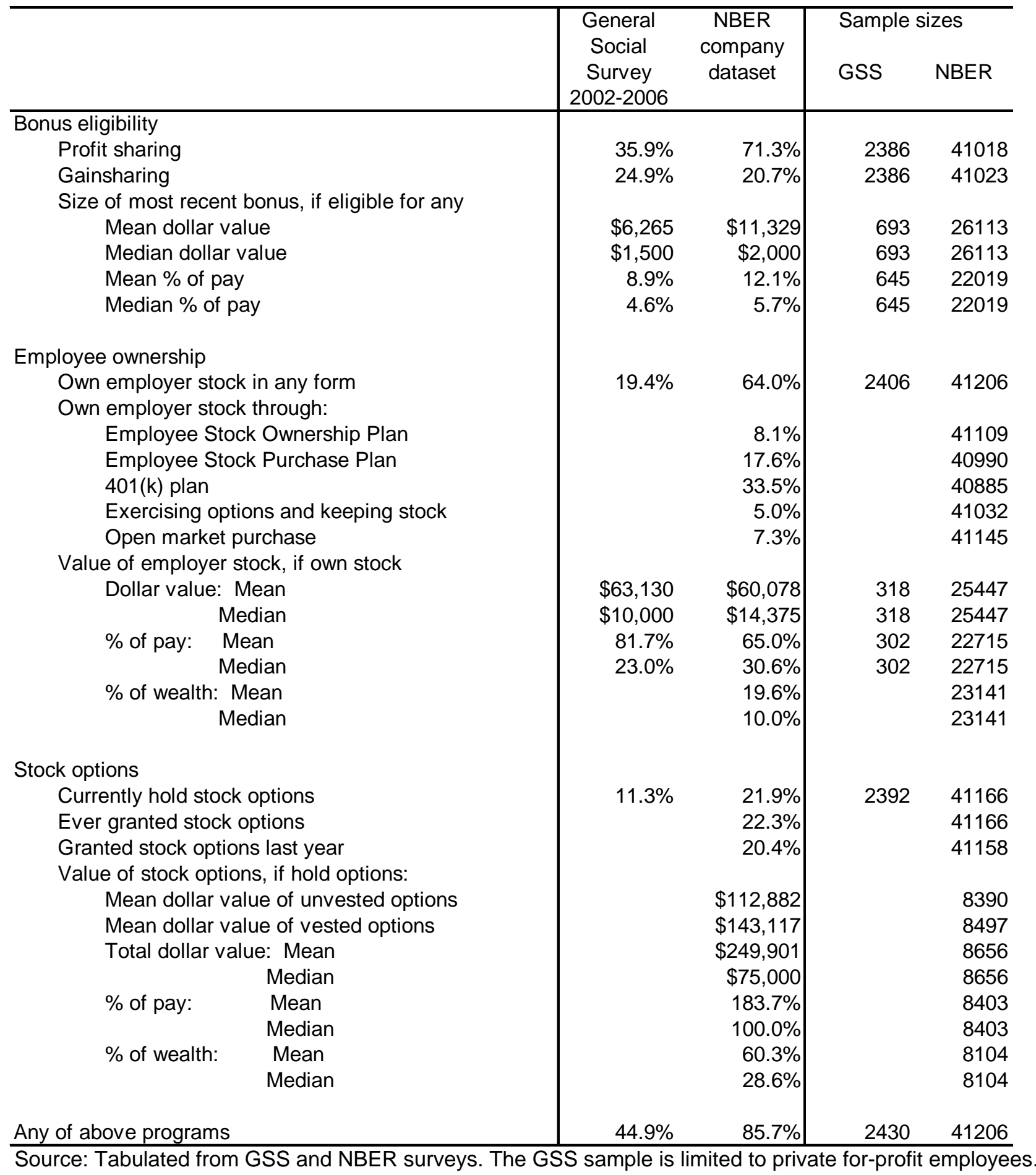

